\title{
A Compression \& Encryption Algorithm on DNA Sequences Using Dynamic Look up Table and Modified Huffman Techniques
}

\author{
Syed Mahamud Hossein \\ Regional Office, Kolaghat; Directorate of Vocational Education \& Training, West Bengal, India \\ E-mail:mahamud123@gmail.com \\ S.Roy \\ HIT, Haldia, India
}

\begin{abstract}
Storing, transmitting and security of DNA sequences are well known research challenge. The problem has got magnified with increasing discovery and availability of DNA sequences. We have represent DNA sequence compression algorithm based on Dynamic Look Up Table (DLUT) and modified Huffman technique. DLUT consists of $4^{3}(64)$ bases that are 64 sub-stings, each sub-string is of 3 bases long. Each sub-string are individually coded by single ASCII code from 33(!) to 96(`) and vice versa. Encode depends on encryption key choose by user from four base pair $\{a$, t.g and $\mathrm{c}$ \}and decode also require decryption key provide by the encoded user. Decoding must require authenticate input for encode the data. The sub-strings are combined into a Dynamic Look up Table based pre-coding routine. This algorithm is tested on reverse; complement \& reverse complement the DNA sequences and also test on artificial DNA sequences of equivalent length. Speed of encryption and security levels are two important measurements for evaluating any encryption system. Due to proliferate of ubiquitous computing system, where digital contents are accessible through resource constraint biological database security concern is very important issue. A lot of research has been made to find an encryption system which can be run effectively in those biological databases. Information security is the most challenging question to protect the data from unauthorized user. The proposed method may protect the data from hackers. It can provide the three tier security, in tier one is ASCII code, in tier two is nucleotide (a,t,g and c) choice by user and tier three is change of label or change of node position in Huffman Tree. Compression of the genome sequences will help to increase the efficiency of their use. The greatest advantage of this algorithm is fast execution, small memory occupation and easy implementation. Since the program to implement the technique have been written originally in the $\mathrm{C}$ language, (Windows XP platform, and TC compiler) it is possible to run in other microcomputers with small changes (depending on platform and Compiler used). The execution is quite
\end{abstract}

fast, all the operations are carried out in fraction of seconds, depending on the required task and on the sequence length. The technique can approach an effective compression ratio of $1.98 \mathrm{bits} / \mathrm{base}$ and even lower. When a user searches for any sequence for an organism, an encrypted compressed sequence file can be sent from the data source to the user. The encrypted compressed file then can be decrypted \& decompressed at the client end resulting in reduced trans mission time over the Internet. An encrypt compression algorithm that provides a moderately high compression with encryption rate with minimal decryption with decompression time.

Index Terms - Compression, Security,

Abbreviation-DLUT-Dynamic Look up Table

\section{Introduction}

With more and more complete genomes of prokaryotes and eukaryotes becoming available and the completion of Human Genome Project on the horizon, fundamental questions regarding the characteristics of these sequences arise. Life represents order. It is not chaotic or random [1]. Thus, we expect the DNA sequences that encode life to be nonrandom. In other words, they should be very compressible. There is also strong biological evidence that supports this claim, it is well known that DNA sequences only consist of four nucleotide bases $\{a, \mathrm{t}, g, \mathrm{c}\}$, (note that $\mathrm{T}$ is replaced with $\mathrm{U}$ in the case of the RNA), and one byte are enough to store each base. All this evidence gives more concrete support that the DNA sequences should be reasonably compressible. It is well recognized that the compression of DNA sequences is a very difficult task [2-6]. However, if one applies standard compression tools such as the Unix "compress" and "compact" or the MS-DOS archive programs "pkzip" and "arj", they all expand the file. These tools are designed for text 
compression [2], while the regularities in DNA sequences are much subtler. It means that DNA sequences do not have the same properties for the traditional compression algorithms to be counted on. This requires a better model for computing the DNA content such that better data compression results can be achieved. In fact, it is our purpose to reveal such subtleties, such as dynamic Look Up Table of 3 letter 64 sub-string, match with source DNA sequences by using a more appropriate compression algorithm. In this article, we will present a DNA compression algorithm, DLUT, based on exact matching between Look Up Table and source file and that gives the best compression results on standard benchmark DNA sequences. We will present the design rationale of dynamic LUT based on exact matching, discuss details of the algorithm, provide experimental results and compare the results with the one most effective compression algorithm for DNA sequence (gzip-9).

We can find the compression rate and compression rate over reverse, complement and reverse complement of DNA sequences result of same cellular DNA sequences. Also we can find the compression rate, compression ratio of artificially sequence generated by randomly of equivalent length of cellular DNA sequence. Compare all result to each other. For that purpose we can generate two different algorithms.

We devised a new DNA sequence compression algorithm based on dynamic Look Up Table precoding routine which maps the 3 letter 64 sub-sting into 64 ASCII characters start from 33(!) to 96 (') and vice versa. Since the essence of compression is a mapping between source file and destination file, the compression algorithm dedicates to find the relationship. We migrate this idea to our research on DNA sequence compression. We are trying to build a finite DLUT which implements the mapping relationship of our coding process. Some experiments indicate that the compression ratio is $3.1 \mathrm{bits} / \mathrm{b}$ ase.

Huffman CODING: Statistical codes represent data blocks of fixed length with variable-length code[7] words. Huffman coding is one type of statistical code[8-9]. This coding is also one type of entropy coding. Entropy encoding is a lossless data compression scheme that is independent of the media's specific characteristics. Entropy coding[10-11] assigns codes to symbols so as to match code lengths with the probabilities of the symbols. Typically, these entropy encoders are used to compress data by replacing symbols represented by equal-length codes with symbols represented by codes where the length of each codeword is proportional to the negative logarithm (is $-\log _{b} P$, where $b$ is the number of symbols used to make output codes and $P$ is the probability of the input symbol) of the probability. Therefore, the most common symbols use the shortest codes.

The efficiency of a Huffman[12-13] code depends on the frequency of occurrence of all distinct fixed length blocks in a set of data. The most frequently occurring blocks are encoded with short code words, whereas the less frequently occurring ones are encoded with large code words. In this way, the average codeword length is minimized. It is obvious however that, if all distinct blocks in a data set appear with the same (or nearly the same) frequency, then no compression can be achieved. Among all statistical codes, Huffman offer the best compression since they provably provide the shortest average codeword length. Another advantageous property of a Huffman code is that it is prefix free; i.e., no codeword is the prefix of another one. This makes the decoding process simple and easy to implement.

Let $T$ be the fully specified test set. Let us also assume that if we partition the test vectors of $T$ into blocks of length $l$, we get $k$ distinct blocks $b 1, b 2, \ldots$, $b k$ with frequencies (probabilities) of occurrence $p 1$, $p 2, \ldots, p k$, respectively. The entropy of the test set is defined as

$$
H(T)=-\sum_{i=1}^{k} P_{i}\left(\log _{2} P_{i}\right)
$$

and corresponds to the minimum average number of bits required for each codeword. The average codeword length of a Huffman code is closer to the aforementioned theoretical entropy bound compared to any other statistical code. In practice, test sets have many don't care $(x)$ bits. In a good encoding strategy, don't cares must be assigned such that the entropy value $H(T)$ is minimized. In other words, the assignment of the test set's $x$ values should skew the occurrence frequencies of the distinct blocks as much as possible. We note that the inherent correlation of the test cubes of $T$ (test vectors with $x$ values) favors the targeted occurrence frequency skewing and, consequently, the use of statistical coding. To generate a Huffman code, we create a binary tree. A leaf node is generated for each distinct block $b i$, and a weight equal to the occurrence probability of block $b i$ is associated with the corresponding node. The pair of nodes with the smallest weights is selected first, and a parent node is generated with weight equal to the sum of the weights of these two nodes. The previous step is repeated iteratively, selecting each time the node pair with the smallest sum of weights, until only a single node is left unselected, i.e., the root (we note that each node can be chosen only once). Starting from the root, we visit all the nodes once, and we assign to each leftchild edge the logic 0 values and to each right-child edge the logic 1 value. The codeword of block bi is the sequence of the logic values of the edges belonging to the path from the root to the leaf node corresponding to bi. If $c 1, c 2, \ldots, c k$ are the codeword lengths of blocks $b 1, b 2, \ldots . ., b k$, respectively, then the average codeword length is 


$$
C(T)=\sum_{i=1}^{k} P_{i} C_{i}
$$

Data Compression and ENCRYPTION: There is a similarity between the process of data compression and process of encryption. The goal for both the processes is to reduce the redundancy in the source message. According to Shannon [14], for perfect lossless compression algorithm, the average bit rate is equal to the source entropy. The redundancy of a source message is the difference between average bit rate and the source entropy of the message. The purpose of reducing the redundancy in case of compression algorithm is to conserver the storage space or communication bandwidth. The goal of reduction of redundancy in case encryption process is to thwart the different cryptanalysis attack based on statistical property of the source message. If we combine both the process of compression and encryption as shown in the fig below, then we can utilize another property of the compression algorithm that the decompression information are concentrated in a few portion of the bit stream, to selectively encrypt those portion of the bit stream which has got more impact on the reconstruction of the message during decompression process, keeping the remaining uncompressed bit stream in the clear.

For a perfect compression scheme, the plain text of the unencrypted portion of the message is statistically independent of the encrypted plain text message. So by knowing the unencrypted plain text, cryptanalyst cannot infer anything for the encrypted plain text.

Due to the combination of the process of compression and the process of encryption, two benefits are realized:

1. Conservation of storage space and commun ication bandwidth

2. Encryption cost is reduced.

3. The attacks on the basis of statistical property of the source bit stream are thwarted.

Client side decompression: We use compression \& selection encryption techniques for the general purpose of sequence data delivery to the client. Existing DNA search engines do not utilize DNA sequence compression algorithms \& encryption for high security for client side decryption $\&$ decompression, i.e. where encrypted compressed DNA sequence is decrypted \& decompressed at the client end for the benefit of faster transmission \& information security. Because most of the existing DNA sequence compression algorithms aim for higher compression ratios or pattern revealing, rather than client side \& decryption decompression, their decompression times are longer than necessary information security. This makes these compression techniques unsuitable for the "on the fly" decompression. We use encrypted compression technique designed for client side decrypted followed by decompression in order to achieve faster sequence secure data transmission to the client.

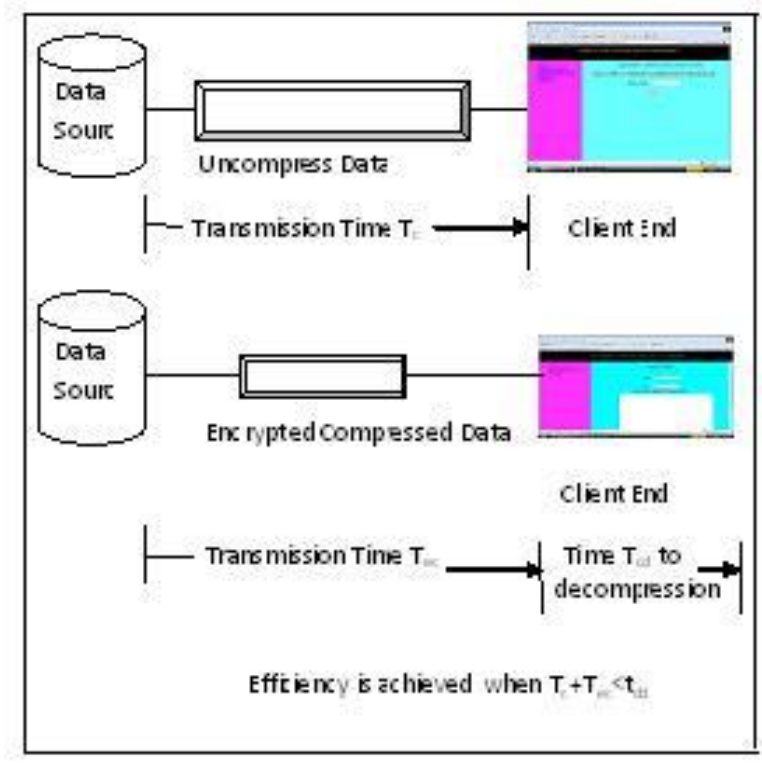

Fig. 1: Sender \& receiver site encryption \& Decryption process

If encrypted compressed sequence data is sent from the data source to be decrypted decompressed at the client end and the decryption to decompression time along with the encrypted compressed file transmission time is less than the transmission time for uncompressed data transfer from the source to the client, then efficiency is achieved. Fig. 1 illustrates the situation. Note that the sequence data should be kept pre-compressed within the data source.

A Sequence compression algorithm with reduced decompression time and moderately high compression rate is the preferred choice for efficient sequence data delivery with faster data transmission. As our target is to minimize decompression time and high information security, we use similar compression techniques to those used in [15], based on a "Two phase" approach, meaning, that the file is compressed followed by encryption or decrypt followed by decompressed while reading it. Unlike "four phase" algorithms there is no need to re-read the input file. Our compression technique is essentially a symbol substitution compression scheme that encodes the sequence by replacing four consecutive nucleotide sequences with ASCI characters. Our technique is to find the best solution for a client side decompression.

Work already carried out : So many biological compression algorithms is available in market as in paper[100 ] where showing that Huffman's code also fails badly on DNA sequences both in the static and adaptive model, because there are only four kind symbols in DNA sequences and the probabilities of 
occurrence of the symbols are not very different. Here this two phase technique solved this problem because after the $1^{\text {st }}$ phase compression we get the 252 ASCII characters' with nucleotide base pair a, t,g \& c.

\section{Flowchart:}

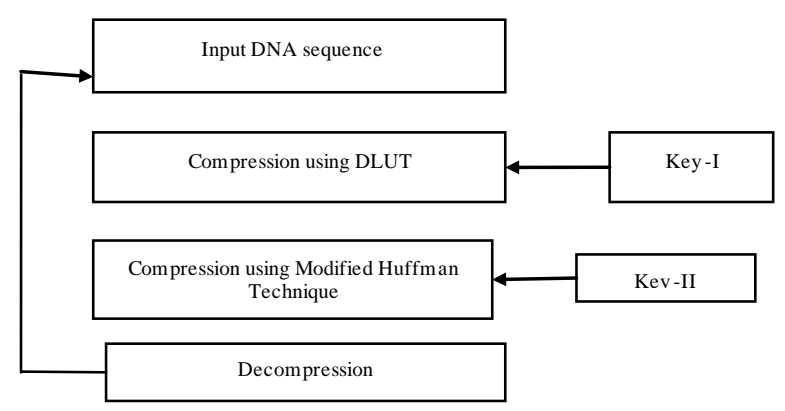

Fig. 2: Process Diagram

\section{Methods}

\subsection{File Format:}

We will begin discussing file type is text file (file extension is dot txt) contain a series of successive four base pair (a,t,g and c ) and end with blank space ahead the end of file. Text file is the basic element to which we consider in compression and decompression. The output file also text file, contains the information of both unmatched four base pair and a coded value of ASCII character.

The coded valued are located in the encoded section. The coded information is written into destination file byte by byte. The file size depends on number of base pair present in the input file and output file measured by byte, i.e. File size (in byte) $=$ number of base pair in a file (in byte).As per example total no. of base pair in a file is $n$, so the file size is $n$ byte. ASCII character also required one byte for storing. On the basis of ASCII code availability, we can take input as a lower case letter of a,t,g and c, if upper case input are taken, algorithm convert into upper case letter to lower case letter.

\subsection{The Four Bases Pair a,t,g and $c$}

The four bases pair a,t,g and c possible orientation $4^{3}=64$. All sub-string has 3 bases long. The look-up table describes a mapping relationship between DNA segment and its corresponding characters. We assume that every three characters in source RNA sequence without $\mathrm{N}^{2}$ will be mapped into a character chosen from the character set which consists of 64 ASCII characters.

Consider a string $S=$ aaaaagaacatgatcttccc ........n where $n$ is the length of string.

So, $n=$ Length of the string $=$ Total no. of base pair in $\mathrm{S}=$ File size in byte $(\mathrm{n}>0)$

Due to DLUT facility we can take input from four base pair \{a,t,g \& c $\}$ in 24(Factorial of 4=24) orientation and all times starting and ending ASCII code range from 33(!) to 96( ) and vice versa. That means DLUT variation are $24 \mathrm{X} 2 \mathrm{i}$,e 48 no different table. We can create 48 different LUT in this way. But all times sub-string in a table is $64\left(4^{3}=64\right), 64$ ASCII code are sufficient to define the one particular LUT in each encoding and decoding time.

${ }^{2} \mathrm{~N}$ Refers to those not available base in DNA sequence

\subsection{Encoding steps:}

First input file encoded by Look Up Table-I, encoded data store on another output file.

Look up Table structure is

Table 1: Lookup Table

\begin{tabular}{|c|c|c|c|c|c|}
\hline \multicolumn{2}{|c|}{ LUT INPUT } & \multicolumn{2}{|c|}{ Structure LUT } & \multicolumn{2}{c|}{ Range of ASC II code A[j] } \\
\hline Sr. No. & Input character & Sr. No. & Sub-string for LUT S[i] & Start from(Increasing) & Start from(Decreasing) \\
\hline 1 & atgc & 1 & aaa & $33 / 96$ & $96 / 33$ \\
& & 3 & aag & & \\
& & 4 & aac & & \\
& & 8 & atg & & \\
& & 24 & atc & & \\
& & ttc & gaa & & \\
& & 64 & ccc & & \\
\hline
\end{tabular}

We match the input string with pre coded LUT. For that purpose we have break the string $S$ into (n-2) sub string, each sub-string has length 3 bases long. n-2 because each sub-string length is 3 . 


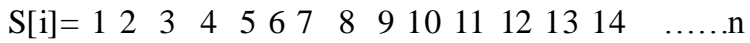
$[1 \leq \mathrm{i} \leq \mathrm{n}]$

As for example: $\mathrm{S}=\mathrm{a}$ a a a a $\mathrm{g}$ a a $\mathrm{c}$ a $\mathrm{t}$ g .........n

$\mathrm{n}=12234567891011121314 \ldots \ldots . n$
Where S[i] array store each sub-string of $\mathrm{S}$ and $\mathrm{i}=1$ to $\mathrm{n}-1$.

$\mathrm{S}[1]=\mathrm{aaa}, \mathrm{S}[2]=\mathrm{aaa}, \mathrm{S}[3]=\mathrm{aaa}$,

$\mathrm{S}[\mathrm{n}-2] \mathrm{ccc}$

Table 2: Sub Group press

\begin{tabular}{|c|c|c|c|c|c|}
\hline Input string $(\mathrm{S})$ & LUT starting charecter & Sub-string A[i] & Match condition $\mathrm{S}[\mathrm{i}]=\mathrm{A}[\mathrm{j}]$ & $\mathrm{ASCII}$ code $\mathrm{A}[\mathrm{j}]$ & Output \\
\hline aaaaaagaacatgatcttccc & atgc & aat & $\mathrm{S}[1]=\mathrm{A}[1]$ aat $=$ & - & $\mathrm{a}$ \\
\hline & & att & $\mathrm{S}[2]=\mathrm{A}[2]$ & & \\
\hline
\end{tabular}

First match S[1] with A[1] to A[64], if match occur place ASCII character in $1^{\text {st }}$ position otherwise left one character in left hand side in $\mathrm{S}$, place $1^{\text {st }}$ character in output file $1^{\text {st }}$ position. This left single character are place output file in $1^{\text {st }}$ position. Progress one character toward in right direction, take next sub-string and match $S$ [2] with $A[1]$ to $A[64]$, if match occur place appropriate ASCII character in $2^{\text {nd }}$ place. This ASCII character is put into the output file in $2^{\text {nd }}$ position. This process will continue until and unless $n-2$ position reaches.

The Encoding procedure mentioned this rule and produce compres sion output file.

Match found then $\mathrm{S}[\mathrm{i}]=\mathrm{A}[\mathrm{j}]$, place ASCII character in the output file $i^{\text {th }}$ position. Each matching cases the value of $\mathrm{i}$ is incremented by $\mathrm{i}=$ no. of unmatched character+ (no. of sub-string match X 3+1)

Otherwise $S[i] \neq A[j]$ place base pair in output file ${ }^{\text {ith }}$ position. If unmatched occur, the value of $i$ is incremented by one and $\mathrm{j}$ is increased by one.
At the end, we can get the compress output file $\mathrm{O}$

So, $\mathrm{O}=$ !!Ac' $\left(8 \mathrm{cc} \ldots \ldots \ldots \ldots \mathrm{n}_{1}\right.$ where $\mathrm{n}_{1}$ is the length of output file. Output file size is $n_{1}$ byte

\subsection{Decoding}

Decoding time, first create LUT(fix base pair which are use in encoding time for single case, its depends on user authenticate value and decryption key and authenticate ASCII code starting position otherwise proper decoding are not possible.

On this basis of input character set and ASCII code starting value, the actual LUT are crated. On this particular value, the encoded output string is decoded and produces the output original file.

Look Up

Table 3: ASCII staring ending point

\begin{tabular}{|c|c|c|c|}
\hline INPUT & \multicolumn{2}{|c|}{ LUT } & ASC II \\
\hline Authenticate Input & Sr. No. & Sub-string for LUT S[i] & Start from(Increasing/decreasing) A[j] \\
\hline atgc & 1 & aaa & 33 \\
& $\cdot$ & $\cdot$ & \\
& 3 & aag & \\
& 7 & aac & \\
& 7 & atg & \\
& 24 & atc & \\
& 33 & ttc & \\
& 64 & gaa & \\
& & & \\
\hline
\end{tabular}

$\mathrm{O}=! ! \mathrm{Ac}^{\prime}(8 \mathrm{cc}$ $n 1$ where $n 1$ is the length of output string $(\mathrm{n}>\mathrm{n} 1)$.

At the time of decoding each character match with ASCII code that is $\mathrm{A}[\mathrm{j}]$ with $\mathrm{O}[\mathrm{i}]$ one by one. If match occur in between $\mathrm{A}[1]$ to $\mathrm{A}[64]$ with $\mathrm{O}[1]$, place ASCII equivalent sub-string in $1^{\text {st }}$ places in output file. The value of $\mathrm{i}$ is incremented by one. If unmatched found in between $\mathrm{A}[1]$ to $\mathrm{A}[64]$ with $\mathrm{O}[2]$, place base pair in $2^{\text {nd }}$ position in output file. The value of $\mathrm{i}$ is incremented by one. This process will continue until $\mathrm{i}=\mathrm{n} 1$ position will appear. 
Table 4: ASCII code decompression

\begin{tabular}{|c|c|c|c|c|}
\hline Input string $(\mathrm{O})$ & LUT starting character & Match condition $\mathrm{A}[\mathrm{j}]=\mathrm{S}[\mathrm{i}]$ & ASCII code $\mathrm{A}[\mathrm{j}]$ & Output \\
\hline$! ! \mathrm{Ac}(8 \mathrm{cc}$ & $\mathrm{atgc}$ & $\mathrm{O}[1]=\mathrm{A}[1]$ aat $=$ & - & $\mathrm{a}$ \\
& & $\mathrm{O}[2]=\mathrm{A}[2]$ & & \\
\hline
\end{tabular}

The Decoding process mentioned this rule and produce original output string.

Match found if $\mathrm{O}[\mathrm{i}]=\mathrm{A}[\mathrm{j}]$ place $\mathrm{ASCII}$ character equivalent sub-string in ith position. If match found, the value of $i$ is incremented by one.

Otherwise $\mathrm{S}[\mathrm{i}] \neq \mathrm{A}[\mathrm{j}]$ place base pair in ${ }^{\mathrm{ith}}$ position in output file. If unmatched occur, the value of $i$ is incremented by one.

For easy implementation, characters a,u,g,c will no longer appear in pre-coded file and A,T,G,C will appear in pre-coded file. For instance, if a segment "aaaaaagaacatgatcttccc .......n" has been read, in the destination file, we represent them as "aDNc9txa.......n. $n_{1}$ ".Obviously, the destination file is case-sensitive

But at the end of file two base segments are remaining (ideal case where total number of base pair are not divisible by 3), We cannot find any arrangement in ASCII table. In these circumstances, we just write the original segment into destination file.

We know that each character require 1 byte ( 8 bit) for storing. Using lookup table compaction ration per word is $3: 1$ when match is found.
In case of above example string length $=21$ that means 21 byte require for storing this string. After encoding on the basis of lookup table of 3 sub string length sizes, reduce string length 9 , require 9 byte for storing this string.

\subsection{Huffman Encoding:}

Consider the test set shown in column 1 of Table I, which consists of four test vectors of length 16 (64 bits overall). If we partition the test vectors into blocks of length 4 , we get 16 occurrences of five distinct blocks. Columns 2 and 3 present those five blocks and their frequencies of occurrence, respectively. Column 4 presents the codeword of Table-5

Table 5.1: Encoded data set

\begin{tabular}{|llll|}
\hline \multicolumn{5}{|c|}{ Encoded data set } \\
\hline 10 & 0 & 110 & 0 \\
110 & 10 & 0 & 1110 \\
0 & 10 & 1111 & 0 \\
10 & 0 & 10 & 0 \\
\hline
\end{tabular}

Table 5: Huffman encoding example

\begin{tabular}{|c|c|c|c|}
\hline Test set & Block & Frequency & Code word \\
\hline \multirow{3}{*}{0000101011111010} & 1010 & $7 / 16$ & 0 \\
\cline { 2 - 4 } 111000010100001 & 0000 & $5 / 16$ & 10 \\
\cline { 2 - 4 } 000000000101010 & 1111 & $2 / 16$ & 110 \\
\cline { 2 - 4 } 00001010 & 0001 & $1 / 16$ & 1110 \\
\cline { 2 - 4 } & 0010 & $1 / 16$ & 1111 \\
\hline
\end{tabular}

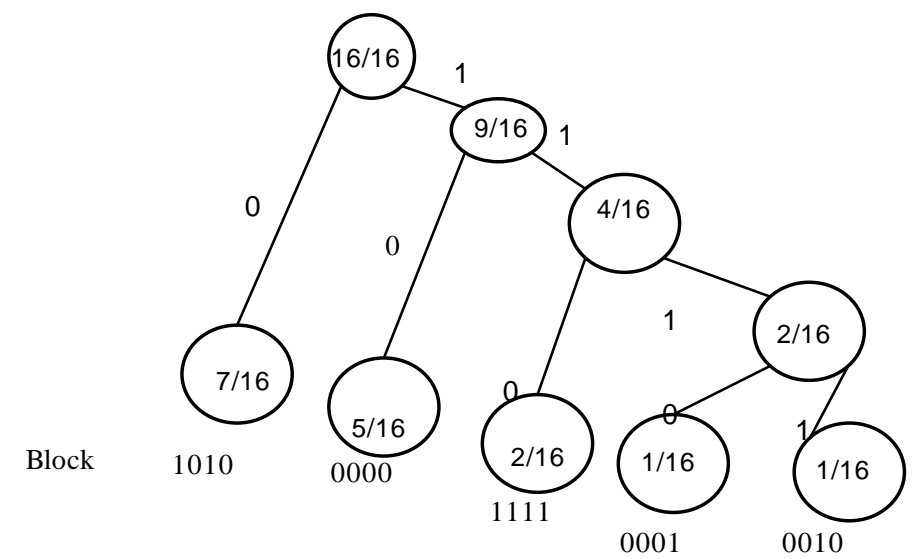

Fig. 3: Left \& right node 
Each block the corresponding Huffman tree and the encoded data set are shown in Fig.2.3. The size of the encoded data set is 31 bits, and the average codeword length is

$$
\begin{aligned}
& \mathrm{C}(\mathrm{T})=1 *(7 / 16)+2 *(5 / 16)+3 *(2 / 16)+4 *(1 / 16)+4 *(1 / 1 \\
& 6)=1.9375
\end{aligned}
$$

Note that the entropy is equal to

$\mathrm{H}(\mathrm{T})=-\left[(7 / 16) * \log _{2}(7 / 16)+(5 / 16) * \log _{2}(5 / 16)+\right.$ $(2 / 16) * \log _{2}(2 / 16)+(1 / 16) * \log _{2}(1 / 16)+(1 / 16) *$ $\left.\log _{2}(1 / 16)\right]=1.9218$

The size of a Huffman decoder depends on the number of distinct blocks that are encoded. Increased encoded-block volumes lead to big decoders due to the big size of the corresponding Huffman tree. For that reason, a selective Huffman approach was adopted in our project, according to which only the most frequently occurring blocks are encoded, whereas the rest are not.

\subsection{Proposed Methods}

\subsubsection{Methodology of Experiments PERFORMED:}

We have conducted our experiments in normal text files of different sizes and on the basis of the statistical property generated by Huffman tree for each text files. Since our objective is to find out the selective portion i.e. $\mathrm{R}$ part (discussed previously) from the text message we made swapping of the branches in the Huffman tree on at a particular level on the basic of a key and decode the encoded symbols using the modified Huffman tree which are specified in scheme I and II. In scheme-I we apply swapping method on two nodes at specified level on Huffman tree, and in scheme-II we perform swapping method between two specified nodes at different level on Huffman tree. When we generate the Huffman tree using the statistical property of symbols, first we consider each character of input text message as a symbol and later each word as a symbol.

Illustrating Huffman Code With Example: We take a simple text containing alphabets A, B, C, D, E, F and their frequencies $8,3,2,4,2,1$ respectively. The Huffman tree in this case would be as in figure below (fig. 4.1).

Table 6: Coding scheme

\begin{tabular}{|c|c|}
\hline Char & Codeword \\
\hline A & 0 \\
\hline C & 100 \\
\hline B & 101 \\
\hline F & 1100 \\
\hline E & 1101 \\
\hline D & 111 \\
\hline
\end{tabular}

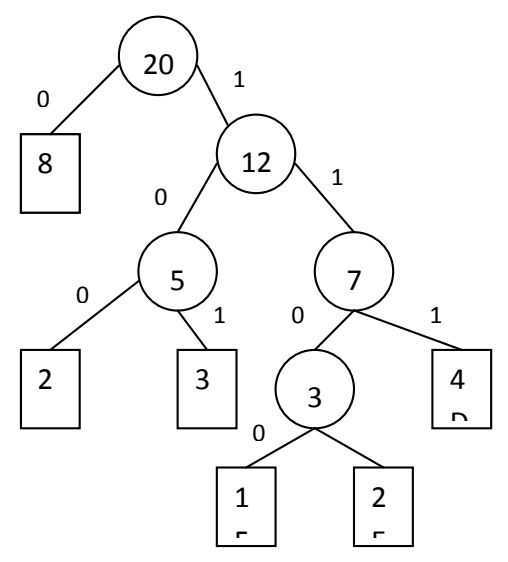

Fig. 4: Binary coding scheme

Example: We take a simple test their frequencies $8,3,2,4,2,1$ would be as in figure above

Suppose we take a string "AABBC", for example, would be encoded as "00101101100". And when we decompress it according to 0 and 1 , we traverse the tree from root to left or right until we get child node. E.g. the bit stream "00101101100". The first two"0" will be decode traversing from root $20 \rightarrow 8$ (A) [left traversing since 0] and next " 1 ", then traversing from root to left $20 \rightarrow 12$, next " 0 ", then traversing from 12 to left $12 \rightarrow 5$, next " 1 ", traversing from 5 to right $5 \rightarrow 3(\mathrm{~B})$ and get leaf node B. Similarly we get original text "AABBC". Thus the original text is decompressed from compressed text.

\subsubsection{Swapping Nodes at Specified Level (Scheme-I)}

Our objective is to find out the selective portion i.e. $\mathrm{R}$ part (discussed previously) from the text message. We made swapping of the branches in the Huffman tree on at a particular level on the basis of a key and decode the encoded symbols using the modified Huffman tree. Now for selecting the R part, my first experiment is swapping two nodes at specified levels. Here I exchange by left most nodes with right most nodes at specified level. So only those nodes, which are changed their positions after swapping, are affects and also corresponding codes are also altered. Remaining other nodes is kept unchanged. Hence selective bits are altered.

Let illustrate this with an example, Fig.4.2 is the original tree and Huffman codes of $\mathrm{W}=00, \mathrm{X}=01$, $\mathrm{Y}=10, \mathrm{Z}=11$.

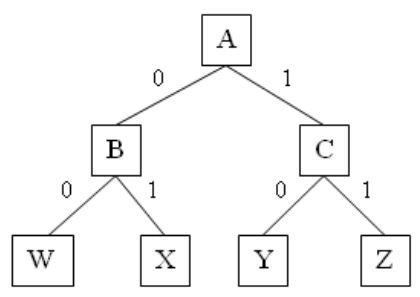

Fig. 5: Code word 
Suppose we apply swapping at level 1 then we find out $\mathrm{A}$ is single node i.e. root node at level 0 i.e. root node at level 0 . Then we interchange the position of left and right child node with their sub tree as shown in fig.4.3. So corresponding code of $\mathrm{W}, \mathrm{X}, \mathrm{Y}, \mathrm{Z}$ are totally changed. $W=10, X=11, Y=00, Z=01$. So if the original text is "WWXYXZ" then it will be encrypted "101011001101". If we decode it without change the level the text will be "YYZWZX". $\mathrm{D}_{\text {SID }}$ in this case is 6 .

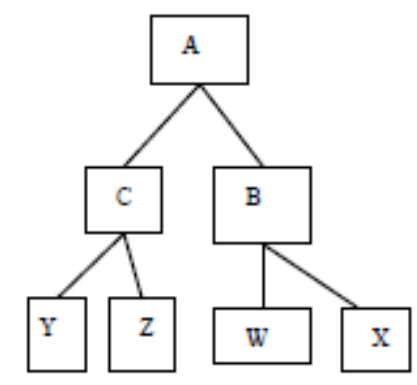

Fig. 6: Tree

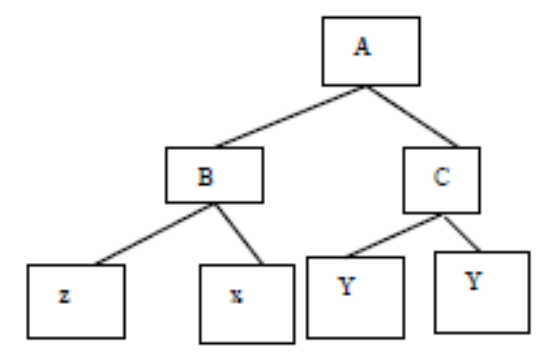

Fig. 7: Tree

Table-7: Binary code

\begin{tabular}{|c|c|c|c|}
\hline \multirow{2}{*}{ Character } & \multirow{2}{*}{$\begin{array}{c}\text { Before } \\
\text { Encrypt }\end{array}$} & \multicolumn{2}{|c|}{ After Encrypt } \\
\cline { 3 - 4 } & & $\begin{array}{c}\text { Swapping at } \\
\text { Level 1 }\end{array}$ & $\begin{array}{c}\text { Swapping at } \\
\text { Level 2 }\end{array}$ \\
\hline $\mathrm{W}$ & 00 & 10 & 11 \\
\hline $\mathrm{X}$ & 01 & 11 & 01 \\
\hline $\mathrm{Y}$ & 10 & 00 & 10 \\
\hline $\mathrm{Z}$ & 11 & 01 & 00 \\
\hline
\end{tabular}

Now we apply swapping at level 2(here B, C) then we interchange the position of left child of $\mathrm{B}$ and right child of $\mathrm{C}$ and with their sub tree as shown in fig.4.4. In this case corresponding codes are selectively changed. i.e. since in fig. 4.4 we see on $\mathrm{W}$ and $\mathrm{Z}$ are interchange their positions so code of $\mathrm{Z}$ and $\mathrm{W}$ are only changed, other should be unchanged according to table 4.1. So if the original text is "WWXYXZ" then it will be encrypted " 111101100100 ". If we decode it without change the level the text will be "ZZXYXW". D in this case is 3 .

The results diverged from our expectations in some simple cases due to the complexities in the alignments of characters when calculating $\mathrm{D}_{\mathrm{SID}}$. In our experiment, when we measure Lavenstein distance and effectness on actual text we face some minor problems.

Suppose we compress a text file-applying node swapping method at particular level. But if we measure effectness on actual text by decoding the encoded text without any swapping method apply, then in some cases all codes may not be retrieved, for e.g. suppose frequency of $\mathrm{A}=2, \mathrm{~B}=1$ and $\mathrm{C}=1$ then tree will be generate like

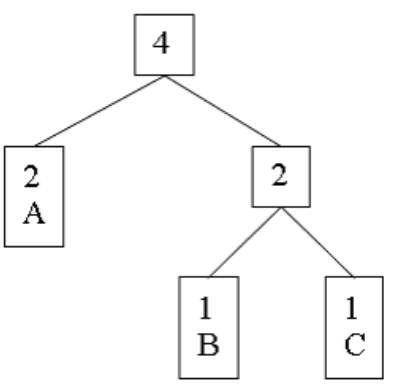

Fig. 8: Tree structure

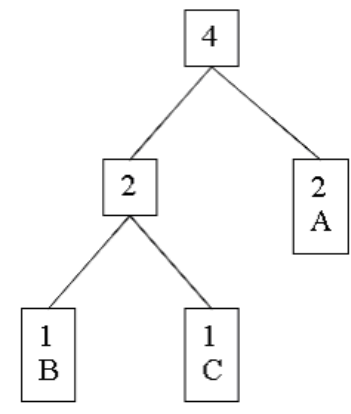

Fig. 9: Tree structure

And their corresponding codeword $\mathrm{A}=0, \mathrm{~B}=10$, $\mathrm{C}=11$.

And suppose the string 'AABBC' would be encoded as 00101011.

Now if we apply swapping method at level 0 then the tree will generate like fig. 4.6

And their corresponding code $\mathrm{A}=1, \mathrm{~B}=00, \mathrm{C}=01$.

And same string then encoded as 11000001 .

Now if we measure Lavenstein distance \& \% of effectness on actual text then we must decode without apply swapping method at level 0 . Then that encoded string is decoded using original tree (fig.4.5).

Table 8: Code Table

\begin{tabular}{|c|c|c|c|c|c|c|c|}
\hline 1 & 1 & 0 & 0 & 0 & 0 & 0 & 1 \\
\hline $\mathrm{C}$ & $\mathrm{C}$ & $\mathrm{A}$ & $\mathrm{A}$ & $\mathrm{A}$ & $\mathrm{A}$ & $\mathrm{A}$ & - \\
\hline
\end{tabular}

The last 1 is left over because there is no such code of only 1 . So for measurement purpose the size of original text is altered in these cases. 


\subsubsection{Swapping between Two Specified Nodes at Different Level (Scheme-II)}

In my second experiment we get another approach for selecting the $\mathrm{r}$ part (discussed previously). In this approach swapping can be perform at any specified two nodes. By this approach we can interchange any two nodes with its sub tree of the Huffman tree at any level. Hence this scheme has flexibility to modify Huffman tree and also use more than one key so it obviously increase security concern. In this scheme we need to specify two level values of two nodes and two binary values. Number of binary digit must be same with level value with respect to nodes. If we consider above specified two values as a key then security concern is improved than before experiment. E.g. Fig.4.7 is the original tree and Huffman codes of $\mathrm{W}=00$, $\mathrm{X}=01, \mathrm{Y}=10, \mathrm{Z}=11$.

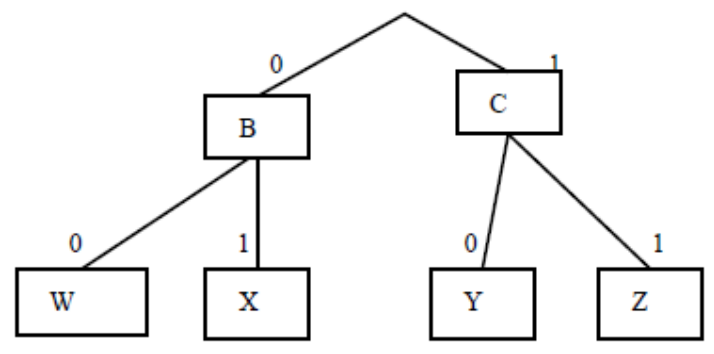

Fig. 10: Binary Tree

Suppose I want to swap between two nodes B and Z then we need to specify first, level number, in this case 1 and binary dig it 0 for $\mathrm{B}$ node and level number for $\mathrm{Z}$, in this case 2 and binary digit 11. Then new tree will generate like

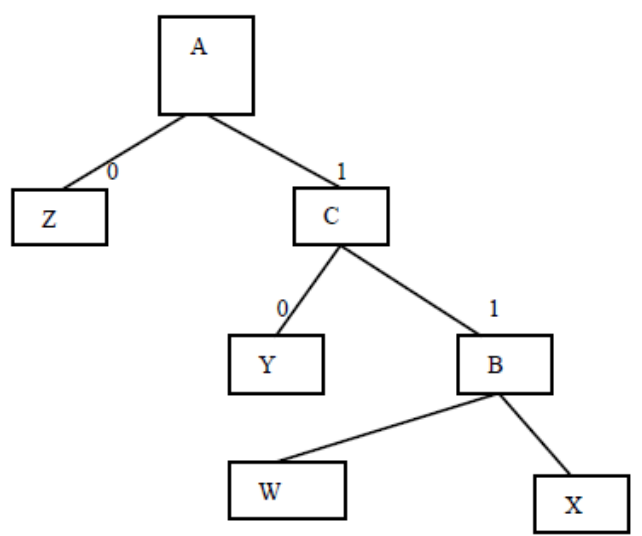

Fig. 11: Binary Tree

After interchanging the position of left and right child node with their sub tree as shown in fig.4.8 so corresponding codes of $\mathrm{W}, \mathrm{X}, \mathrm{Y}, \mathrm{Z}$ are totally changed according to table 4.2. So if the original text is "WWXYXZ" then it will be encrypted "110110111101110". If we decode it without change the level the text will be decrypt like "ZXYZZXZ". $\mathrm{D}_{\text {SID }}$ in this case is 6 .
Table 9: Character corresponding code word

\begin{tabular}{|c|c|c|c|}
\hline \multirow{2}{*}{ Character } & \multirow{2}{*}{ Before Encrypt } & \multicolumn{2}{|c|}{ After Encrypt } \\
\cline { 3 - 4 } & $\begin{array}{c}\text { Swapping } \\
\text { between } \\
\text { B and Z }\end{array}$ & $\begin{array}{c}\text { Swapping } \\
\text { between } \\
\text { C and X }\end{array}$ \\
\hline $\mathrm{W}$ & 00 & 110 & 00 \\
\hline $\mathrm{X}$ & 01 & 111 & 1 \\
\hline $\mathrm{Y}$ & 10 & 10 & 010 \\
\hline $\mathrm{Z}$ & 11 & 0 & 011 \\
\hline
\end{tabular}

\subsection{Random String Generation Method:}

We have generate a string of four sy mbols (a,t,g and c) of any arbitrary length, it is user requirement.

This method simply uses random function in $\mathrm{C}++$ language.

\subsection{Reverse, Complement and Reverse Complement Method}

Suppose the original string is

$\mathrm{S}=$ aaaaaagaacatgatcttccc ........n

Reverse string is $\mathrm{R}=\mathrm{n}$............ccttctagtacaagaaaaa

Complement string is $=$ tttttcttgtctagaggg..........n

Reverse Complement is $\mathrm{RC}=\mathrm{n}$....gggaagatgttgttttt

Where $n$ is the length of the string.

\subsection{We Have Develop Four Algorithms}

First: encoding (compression) algorithm, Second: decoding(decompression) algorithm, Third: Random string generator algorithm and Fourth is Reverse, complement and Reverse complement algorithms.

\section{Following Algorithm Are:}

\subsection{Algorithm for Random String Generator}

Procedure Generate

\begin{tabular}{ll}
\hline do & \\
& Integer $i, j ;$ \\
& characterA[]="atcg"; \\
& Input("\%ld",\&j); \\
& FILE *fp; \\
& fp=Open_file( "input.txt", "w"); \\
& for $(i=0 ; i<j ; i++)$ \\
& do \\
& Write_charcter(A[generate_random_num(4)], \\
$f p) ; \quad$ & \\
& end \\
& fclose $(f p) ;$ \\
end &
\end{tabular}




\subsection{Reverse, Complement and Complement the String Algorithm:}

Procedure comp(Character $\mathrm{x}$,Integer $\mathrm{p}$ )

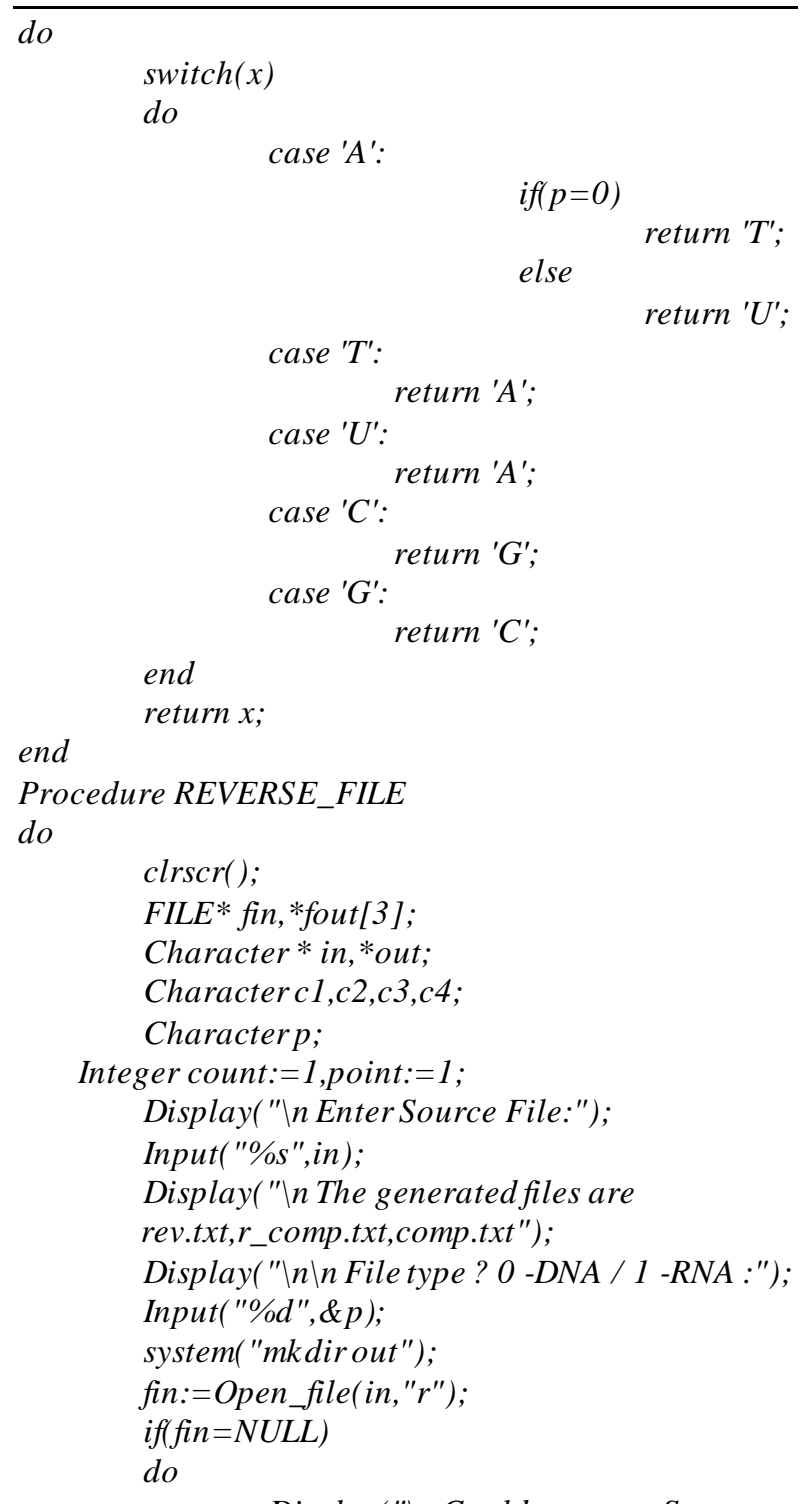

File.");

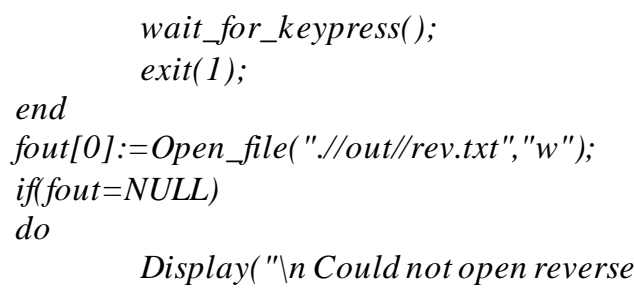

File.");

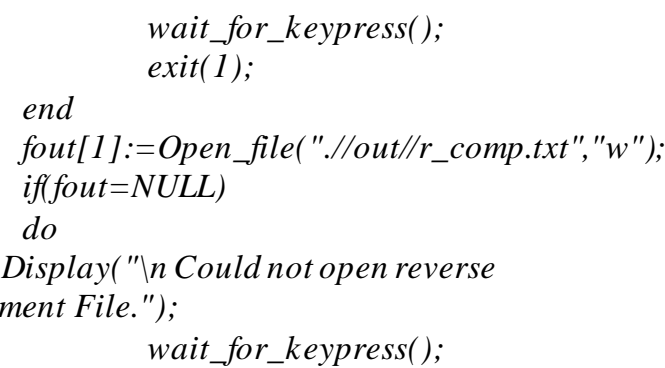

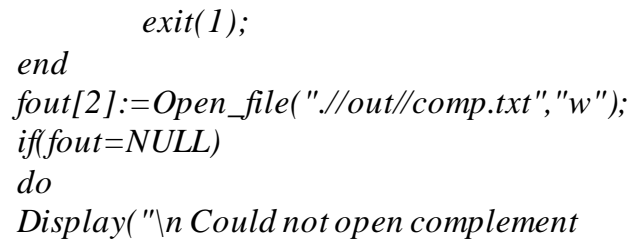

Put_Char_in_File (comp $(c 1, p)$, fout [1]); endwhile(point); close_file(fin); close_file(fout[0]); close_file(fout [1]); close_file(fout[2]);

end

\subsection{Algorithm for DLUT}

\subsubsection{DLUT Encoding algorithm}

Integer: eger: parse(Character : *tx);

Procedure check (Character: ch)

do

if (ch<97 AND ch > 64) return ch +32 ;

return ch;

end;

Character: cod[4][4][4];

Character: LUT[4],vbx[20];

Real : ibytes,obytes;

Procedure ret_pos(Character: $x$ )

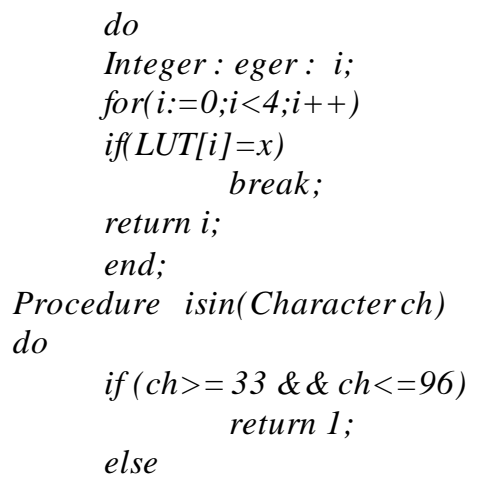


end;

return 0 ;

Procedure parse(Character: *tx)

do

Integer : eger : $p, q, r$;

$p:=r e t \_p o s(t x[0])$

$q:=$ ret_pos $\left._{\mathbf{t}} \mathrm{tx}[1]\right)$;

$r:=r e t \_p o s(t x[2])$;

return $\operatorname{cod}[p][q][r]$;

end;

Procedure Compress_Input()

do

struct time st,sp;

Real : crl,cr2,crate;

FILE *fp, *ip, *op;

Character: BUT[3];

Integer : i,p,q,r,order,rorder;

Character: ch;

Integer: match, $1, t 2$;

Display " Input 3 LUT initializing Character : acters:

$(a, t, c, g) "$;

Display " 1:";

LUT[0]:=get_character();

Display " 2:";

LUT[1]:=get_character ();

Display " 3:";

LUT[2]:=get_character( );

iff LUT[0]<>'a' AND LUT[1] > ' $a^{\prime}$ AND

LUT[2]<>' $a^{\prime}$

LUT[3]:=' $a$;

iff $L U T[0]<>{ }^{\prime} t^{\prime}$ AND LUT[1] ${ }^{\prime}{ }^{\prime} t^{\prime} A N D$

LUT[2]<>' $\left.t^{\prime}\right)$

$$
\text { LUT[3]:=' } t \text {; }
$$

if $\left(\text { LUT[0] <>' } g^{\prime} \text { AND LUT[1] }>\right\rangle^{\prime} g^{\prime}$ AND

LUT $\left.[2]<>g^{\prime}\right)$

$$
\text { LUT [3]:=' } g^{\prime}
$$

if $\left(\right.$ LUT $[0]<>^{\prime} c^{\prime}$ AND LUT[1] $<>^{\prime} c^{\prime}$ AND

LUT $\left.[2]<>^{\prime} c^{\prime}\right)$

LUT[3]:=' $c^{\prime}$;

Display " 4:"<<LUT[3];

do

Display " LUT ordering (33/96)";

Get_User_Input order;

while (order $<>33$ AND order $<>96)$;

if $($ order $=33$ )

rorder: $=96$;

else

rorder: $=33$;

for $(i:=0 ; i<64 ; i++)$

do

$$
\begin{aligned}
& p:=i / 16 ; \\
& q:=(i-p * 16) / 4 ; \\
& r:=i-p * 16-q * 4 ;
\end{aligned}
$$

$\operatorname{cod}[p][q][r \% 4]:=($ order $=33) ?$ order $+i:$ order -

$i$;

end;

Display "LUT generated:";

$f p:=$ fopen ("LUT.txt", " $w ")$;

for $(i:=0 ; i<64 ; i++)$

do

$$
\begin{aligned}
& p:=i / 16 ; \\
& q:=\left(i-p^{*} 16\right) / 4 ; \\
& r:=i-p * 16-q * 4 ; \\
& \text { Write_to_FIle: }
\end{aligned}
$$

(fp," \%d \%c\%c\%c: \%c",i+1,LUT[p],LUT[q],LUT[r] $, \operatorname{cod}[p][q][r])$;

end;

Close_File $(f p)$;

Display " Enter input file:";

Get_User_Input vbx;

ip:=fopen $\left(v b x, " r^{\prime \prime}\right)$;

if $($ ip $=N U L L)$

do

Display " Unable to open input file.";

$\operatorname{exit}(1)$

end;

Display " Enter name for output file:";

Get_User_Input vbx;

$o p:=\operatorname{fopen}(v b x, " w ")$;

if $(o p=N U L L)$

do

Display " Unable to open output file.";

$\operatorname{exit}(1)$;

end;

ibytes: $=$ obytes: $=$ match $:=0$;

gettime (\&st);

gettime (\&sp)

gettime (\&st);

Display (" Start time

is : \%d:\%d:\%d.\%d",st.ti_hour,st.ti_min,st.ti_sec,st.ti_h und);

do

ch: $=$ fgetc $(i p)$;

ch: $=\operatorname{check}(\mathrm{ch})$;

if $(c h=E O F)$

break;

if $($ ret_pos $($ ch $)>2)$

do

Put_Char_to_File(ch,op);

end;

else

do

$B U T[0]:=c h$;

if $(c h=E O F)$

break;

BUT[1]:=fgetc(ip);

BUT[1]:= $\operatorname{check}(B U T[1])$;

if $(B U T[1]=E O F)$

do

Put_Char_to_File(ch,op); break;

end;

BUT[2]:=fgetc(ip);

$B U T[2]:=\operatorname{check}(B U T[2])$;

if $(B U T[2]=E O F)$

do

Put_Char_to_File(ch,op); 


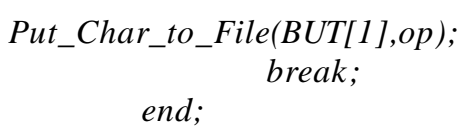

Put_Char_to_File(parse $(B U T), o p)$; match ++ ; end;

while $($ ch $<>E O F)$;

gettime ( \& sp);

Display (" Completed

at :\%d:\%d:\%d.\%d",sp.ti_hour,sp.ti_min,sp.ti_sec,sp.ti _hund);

t1:=st.ti_hund + st.ti_sec*100+st.ti_min $* 6000+$ st.ti_ hour*360000;

$t 2:=s p . t i \_h u n d+s p . t i \_s e c * 100+$ sp.ti_min $* 6000+s p . t$

i_hour*360000;

ibytes: $=$ ftell $($ ip $)$;

obytes: $=$ ftell $($ op $)$;

Close_File (op);

Close_File (ip);

crl $:=(($ ibytes-obytes $) /$ ibytes $* 100)$;

crate $:=($ obytes $* 8) /$ ibytes $;$

cr $2:=((1-$ crate $/ 2) * 100)$;

Display "Input Size: "<<ibytes<<"bytes";

Display " output Size: "<<obytes <<"bytes";

Display " Total words matched from

LUT :"<<match;

Display " Compresstion ratio: $"<<c r l$;

Display " Biological compression ratio: "<<cr2;

Display " Compresstion rate :"<<rate;

Display " Total Time taken: $"<<(t 2-t 1)<<"$

hundreths seconds";

end;

\subsubsection{DLUT Decoding algorithm}

Character: LUT[4],vbx[20];

Procedure Decompress ()

\footnotetext{
do

struct time st,sp;

FILE *fp, *ip, *op;

Integer : i,p,q,r,order,rorder;

Integer : $11, t 2$;

Character : ch;

Display " Input 3 LUT initializing Characters:

$(a, t, c, g) "$;

Display " 1:";

LUT[0]=get_character ();

Display " 2:";

LUT[1]=get_character();

Display " 3:";

LUT[2] = get_character ();

if $\left(\right.$ LUT[0]! =' $a^{\prime} \& \&$ LUT[1]! =' $a^{\prime} \& \&$ LUT[2]! =' $\left.a^{\prime}\right)$ $\operatorname{LUT}[3]={ }^{\prime} a$;

iff LUT[0]! ' ' $t$ ' \& \& LUT[1] ! ='t' \& \& LUT[2]! =' $\left.t^{\prime}\right)$ LUT[3] =' $t$ ';

if $\left(\right.$ LUT [0]! =' $g^{\prime} \& \&$ LUT[1]! =' $g^{\prime} \& \&$ LUT[2] $\left.!={ }^{\prime} g^{\prime}\right)$ $\operatorname{LUT}[3]={ }^{\prime} g^{\prime}$;
}

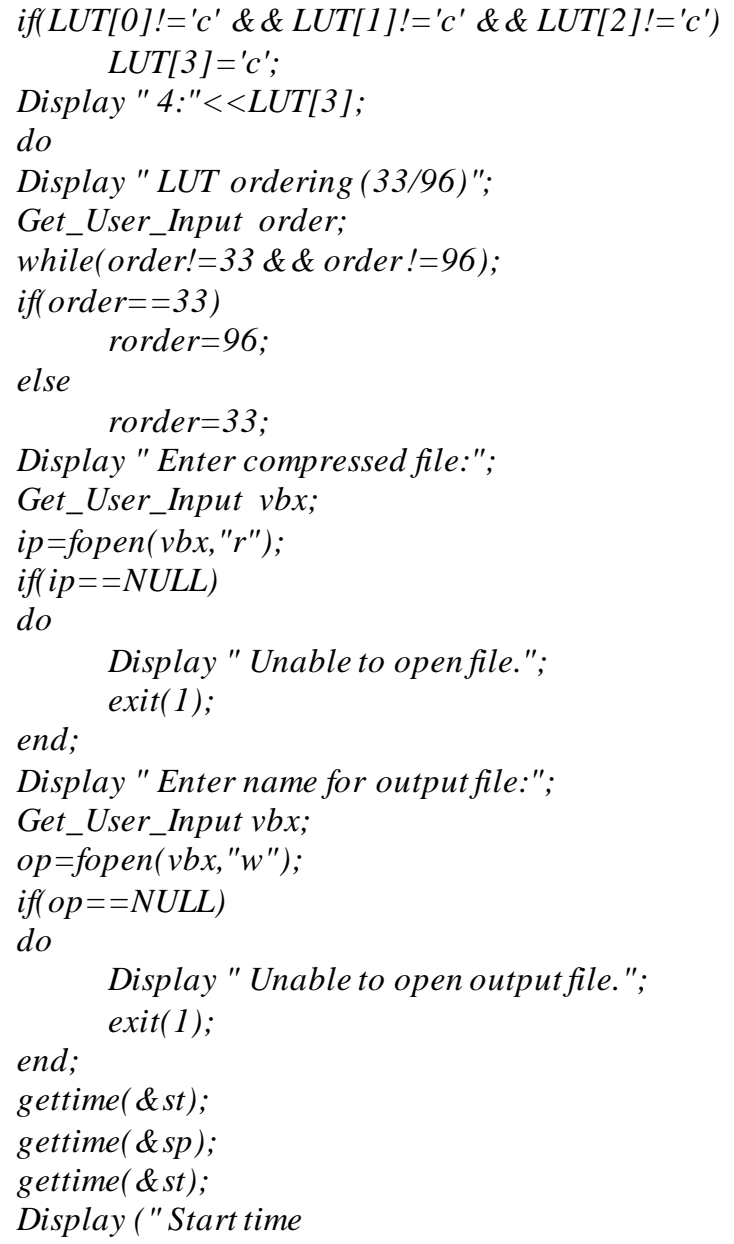

at :\%d:\%d:\%d.\%d",sp.ti_hour,sp.ti_min,sp.ti_sec,sp.ti _hund); 


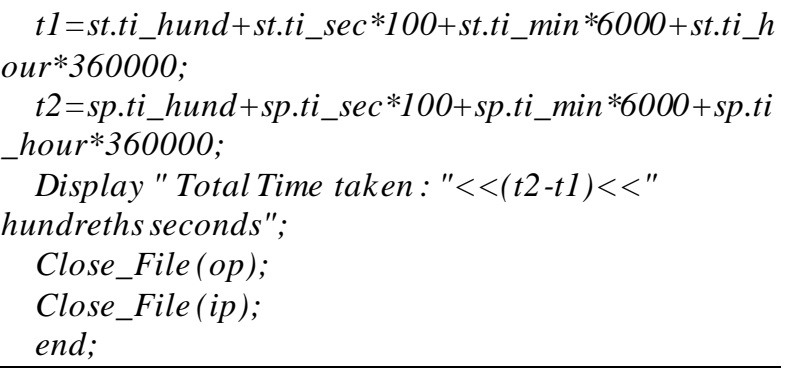

\subsection{Huffman Algorithm:}

This algorithm recursively find a weighted binary tree with $\mathrm{n}$ given weights $\mathrm{w}_{1}, \mathrm{w}_{2}, \ldots \mathrm{w}_{\mathrm{n}}$. (Here weights mean frequency of $\mathrm{n}$ characters in text).

1. Arrange the weights in increasing weights.

2. Construct two leaf vertices with minimum weights, say $w_{i}$ and $w_{j}$ in the given weight sequence and parent vertex of weight $\mathrm{w}_{\mathrm{i}}+\mathrm{w}_{\mathrm{j}}$.

3. Rearrange remaining weights (excluding $w_{i}$ and $w_{j}$ but including parent vertex of weight $\mathrm{w}_{\mathrm{i}}+\mathrm{w}_{\mathrm{j}}$ ) in increasing order.

4. Repeat step 2 until no weight remains.

5. To find out Huffman code for each given weights (i.e. frequency of characters) traversing tree from root assign 0 when traverse left of each node \& 1 when traverse right of each node.

\subsection{Proposed Algorithm for Scheme-I:}

This algorithm recursively find a weighted binary tree with $\mathrm{n}$ given weights $\mathrm{w}_{1}, \mathrm{w}_{2}, \ldots \mathrm{w}_{\mathrm{n}}$. (Here weights mean frequency of $n$ characters in text). LEVEL is the input where the tree is altered.

1. Arrange the weights in increasing weights.

2. Construct two leaf vertices with minimum weights, say $w_{i}$ and $w_{j}$ in the given weight sequence and parent vertex of weight $w_{i}+w_{j}$.

3. Rearrange remaining weights (excluding $w_{i}$ and $w_{j}$ but including parent vertex of weight $\mathrm{w}_{\mathrm{i}}+\mathrm{w}_{\mathrm{j}}$ ) in increasing order.

4. Repeat step 2 until no weight remains.

5. Find out left most nodes and right most nodes at specified LEVEL and interchange their position with respect to their parent node.

6. To find out code for each given weights (i.e. frequency of characters) traversing tree from root assign 0 when traverse left of each node \& 1 when traverse right of each node.

\subsection{Proposed Algorithm for scheme-II:}

This algorithm recursively find a weighted binary tree with $\mathrm{n}$ given weights $\mathrm{w}_{1}, \mathrm{w}_{2}, \ldots . \mathrm{w}_{\mathrm{n}}$. (Here weights mean frequency of $\mathrm{n}$ characters in text). LEVEL is the input where the tree is altered.

1. Arrange the weights in increasing weights.

2. Construct two leaf vertices with minimu meights, say $w_{i}$ and $w_{j}$ in the given weight sequence and parent vertex of weight $w_{i}+w_{j}$.

3. Rearrange remaining weights (excluding $w_{i}$ and $w_{j}$ but including parent vertex of weight $\left.w_{i}+w_{j}\right)$ in increasing order.

4. Repeat step 2 until no weight remains.

5. Find out two nodes at specified LEVEL by binary digits and interchange their position with respect to their parent node.

6. To find out code for each given weights (i.e. frequency of characters) traversing tree from root assign 0 when traverse left of each node \& 1 when traverse right of each node.

\subsection{Algorithm for file mapping}

- Step1 : frame_size $=\operatorname{LENGTH}($ String_1);

- Step2: Repeat step 3 to 5 while String_1 is NULL.

- Step3 : Index=MISMATCHINDEX(String_1,String_2).

- Step4 : IF Index>Length(String_1)-1 then goto step 6.

- Step5 : IF Index=Length(String_1)-1 then String_ $1=N U L L$. ELSE

String_1=SUBSTRING $($ String_1,(Index +1$))$.

String_2=SUBSTRING(String_2,(Index +1$))$.

- Step6 : Error_no=Error_no +1 .

- Step7 : Percentage $=(($ Frame_size Error_no)/Frame_size)*100.

- Step8: Return Percentage.

\section{Algorithm Evaluation}

\subsection{Accuracy}

As to the DNA sequence storage, accuracy must be taken firstly in that even a single base mutation, insertion, deletion or SNP would result in huge change of phenotype as we see in the sicklemia. It is not tolerable that any mistake exists either in compression or in decompression. Although not yet proved 
mathematically, it could be infer from DLUT that our algorithm is accuracy, since every base arrangement uniquely corresponds to an ASCII character.

\subsection{Efficiency}

You can see that the pre-coding algorithm can compress original file from 3 characters into 1 character for any DNA segment and destination file uses less ASCII character to represent successive DNA bases than source file.

\subsection{Time Elapsed}

Today many compression algorithms are highly desirable, but they require considerable time to execute. As our algorithm is based on a DLUT rather than sequence statistics, it can save the time of obtaining statistic information of sequence, and more, after the pre-coding routine, the character number is $1 / 3$ of source one. You can see the elapsed time of our algorithm is in fraction of second.

\subsection{Space Occupation}

Our algorithm reads characters from source file and writes them immediately into destination file. It costs very small memory space to store only a few characters. The space occupation is in constant level. In our experiments, the OS has no swap partition. All performance can be done in main memory which is only $512 \mathrm{MB}$ on our PC.

\section{Experimental Results}

We tested DLUT on standard benchmark data used in [17]. For testing purpose we use two types of data sets. These standard sequences come from a variety of sources and include the complete genomes of two mitochondria: MPOMTCG, PANMTPACGA (also called MIPACGA), two chloroplasts: CHNTXX and CHMPXX (also called MPOCPCG); five sequences from humans: HUMGHCSA, HUMHBB, HUMHDA BCD, HUMDYSTROP, HUMHPRTB; and finally the complete genome from two viruses: VACCG and HEHCMVCG (also called HS5HCMVCG).

These tests are performed on a computer whose CPU is Intel P-IV $3.0 \mathrm{GHz}$ core 2 duo(1024FSB), Intel 946 original mother board, IGB DDR2 Hynix, 160GB SATA HDD Segate.

The definition of the compression ratio ${ }^{1}$ is the same as in [18-19]; i.e., $1-(|\mathrm{O}| / 2|I|)$, where $|I|$ is number of bases in the input DNA sequence and $|\mathrm{O}|$ is the length (number of bits) of the output sequence, other compression ratio $^{2}$ which is defined as $1-(|\mathrm{O}| /|I|)$, where $|I|$ is the length(number of byte) number of bases in the input DNA sequence and $|\mathrm{O}|$ is the length (number of byte) of the output sequence. The compression rate, which is defined as $(|\mathrm{O} /| I \mid)$, where $|I|$ is number of bases in the input DNA sequence and $|\mathrm{O}|$ is the length (number of bits) of the output sequence. The improvement[9] over gzip-9, which is defined as ( Ratio_of_gzip-9 - Ratio_of_LUT-3)/Ratio_of_gzip-9 $* 100$ or Improvement $=(($ Ratio_of_HUFFLUTRatio_of_DLUT)/ Ratio_of_HUFFLUT).The compression ratio and compression rate are presented in Table-10 \& Table-11. Our result compared with gzip-9[20] in the same table.

Compression ratio and Compression rate and speed for the DNA sequences shown in Table I to Table-IV. From top to bottom, each row displays the result for an algorithm showing average compression and decompression speed in seconds per input byte (average computed over five runs for each sequence)."encode" means compression while "decode" mean decompression. Each operation is evaluated in two units, CPU clock and second.

\section{Using Scheme-I}

Table 14: Encryption using following levels

\begin{tabular}{|c|c|c|c|}
\hline $\begin{array}{c}\text { File size } \\
\text { (byte) }\end{array}$ & $\begin{array}{l}\text { Weighted } \\
\text { Frequency } \\
\text { for input } \\
\text { file }\end{array}$ & level & $\begin{array}{l}\text { Weighted } \\
\text { frequency } \\
\text { output file }\end{array}$ \\
\hline \multirow{3}{*}{7550} & \multirow{3}{*}{162} & 2 & 20 \\
\hline & & 3 & 20 \\
\hline & & 4 & 19 \\
\hline \multirow{3}{*}{11358} & \multirow{3}{*}{183} & 2 & 26 \\
\hline & & 3 & 25 \\
\hline & & 4 & 25 \\
\hline \multirow{3}{*}{26655} & \multirow{3}{*}{434} & 2 & 59 \\
\hline & & 3 & 59 \\
\hline & & 4 & 58 \\
\hline \multirow{3}{*}{59890} & \multirow{3}{*}{778} & 2 & 124 \\
\hline & & 3 & 124 \\
\hline & & 4 & 123 \\
\hline
\end{tabular}

We measure weighted frequency for different input and output text shown in table-14. We can conclude that weighted frequency of an input text and encrypted text are maintaining approx $8: 1$ ratio. That mean in case of input te xt and output text, nu mber of characters having same frequency maintains the ratio nearly $8: 1$. So the chance of frequency analysis attack is reduced. 
Table 10: Compression Ratio \& Rate are shown in the Table for first data set

\begin{tabular}{|c|c|c|c|c|c|c|c|c|c|c|c|c|c|c|c|c|c|c|c|}
\hline \multirow{4}{*}{$\begin{array}{l}\mathscr{\Xi} \\
\bar{\Xi} \\
\bar{\Xi} \\
\tilde{D}\end{array}$} & \multirow{4}{*}{ 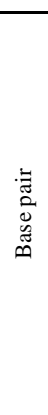 } & \multirow{4}{*}{ 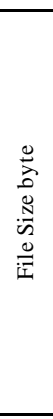 } & \multicolumn{10}{|c|}{ Cellular DNA } & \multicolumn{7}{|c|}{ Artificial DNA } \\
\hline & & & \multicolumn{2}{|c|}{ 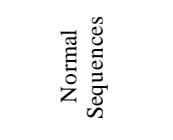 } & \multicolumn{2}{|c|}{ 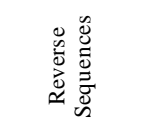 } & \multicolumn{2}{|c|}{ 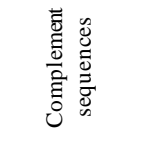 } & \multicolumn{2}{|c|}{ 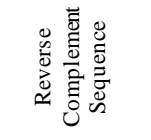 } & \multirow{2}{*}{\multicolumn{2}{|c|}{ 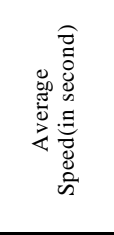 }} & \multirow{3}{*}{ 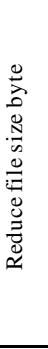 } & \multirow{3}{*}{ 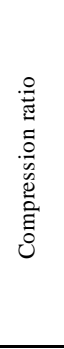 } & \multirow{3}{*}{ 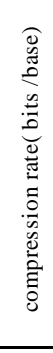 } & \multirow{3}{*}{ 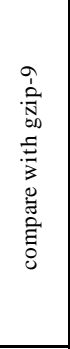 } & \multirow{3}{*}{ 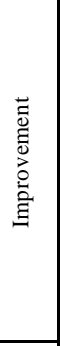 } & \multirow{2}{*}{\multicolumn{2}{|c|}{ 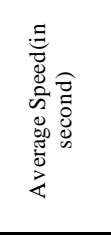 }} \\
\hline & & & 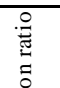 & 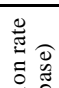 & 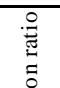 & 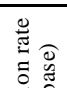 & 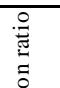 & 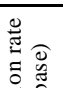 & 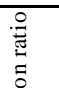 & 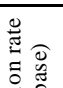 & & & & & & & & & \\
\hline & & & 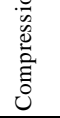 & ل & 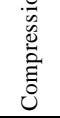 & إن & 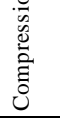 & 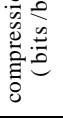 & 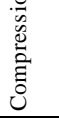 & 象 & 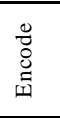 & 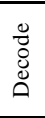 & & & & & & 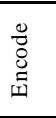 & 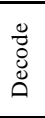 \\
\hline 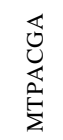 & $\begin{array}{l}\frac{t}{\hat{m}} \\
\stackrel{\Delta}{\mathrm{g}}\end{array}$ & $\begin{array}{l}\stackrel{ \pm}{\mathrm{m}} \\
\stackrel{\mathrm{o}}{\mathrm{O}}\end{array}$ & $\begin{array}{l}\bar{\infty} \\
\infty \\
\vdots \\
\vdots \\
b \\
y\end{array}$ & $\begin{array}{l}\hat{a} \\
\overrightarrow{\vec{a}}\end{array}$ & 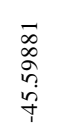 & $\begin{array}{l}\hat{a} \\
\vec{\partial} \\
\vec{i}\end{array}$ & 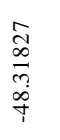 & $\begin{array}{l}0 \\
\stackrel{0}{0} \\
\stackrel{0}{0} \\
\text { ì }\end{array}$ & 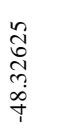 & 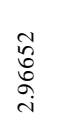 & $\frac{8}{v}$ & $\frac{\circ}{v}$ & 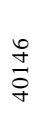 & $\begin{array}{l}m \\
\stackrel{m}{0} \\
\infty \\
0 \\
0 \\
0 \\
1\end{array}$ & 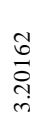 & & & $\frac{8}{v}$ & $\frac{\&}{v}$ \\
\hline 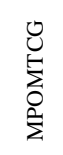 & $\begin{array}{l}\infty \\
0 \\
0 \\
\infty \\
\infty\end{array}$ & $\begin{array}{l}\infty \\
0 \\
0 \\
\infty \\
\infty\end{array}$ & $\begin{array}{l}\overrightarrow{\overrightarrow{0}} \\
\dot{0} \\
\dot{0} \\
\vec{r}\end{array}$ & 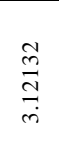 & $\begin{array}{l}\overrightarrow{0} \\
\dot{0} \\
\dot{0} \\
\dot{b} \\
i\end{array}$ & 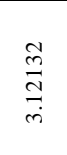 & 胥 & 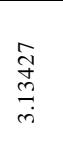 & $\underset{\substack{n \\
m \\
\stackrel{i}{0} \\
i}}{i}$ & 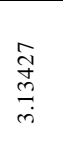 & $\approx$ & 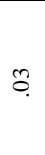 & 先 & 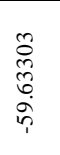 & 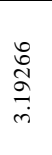 & & & $\frac{\&}{v}$ & $\frac{\&}{v}$ \\
\hline 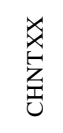 & $\begin{array}{l}\text { 声 } \\
\infty \\
n \\
n\end{array}$ & 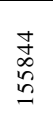 & 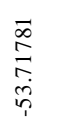 & 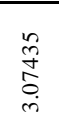 & $\begin{array}{l}\vec{\infty} \\
\stackrel{0}{a} \\
\vec{n} \\
i\end{array}$ & 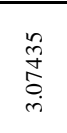 & $\begin{array}{l}\text { ñ } \\
\text { ñ } \\
\text { ì } \\
\text { r. }\end{array}$ & $\begin{array}{l}n \\
2 \\
n \\
n \\
o \\
n \\
n\end{array}$ & $\begin{array}{l}\stackrel{n}{i} \\
\stackrel{n}{c} \\
i \\
i\end{array}$ & 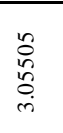 & $\stackrel{8}{\mathrm{v}}$ & $\frac{8}{v}$ & 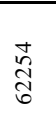 & \begin{tabular}{l}
$y$ \\
\multirow{2}{*}{} \\
$\infty$ \\
$\infty$ \\
$\vdots$ \\
$\vdots$
\end{tabular} & 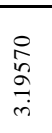 & & & $\frac{\&}{v}$ & $\frac{\&}{v}$ \\
\hline 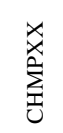 & $\frac{\text { I }}{\stackrel{\text { I }}{0}}$ & 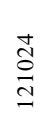 & 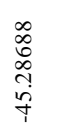 & $\begin{array}{l}\text { ch } \\
\text { à } \\
\text { iे }\end{array}$ & 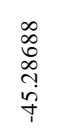 & $\begin{array}{c}\text { के } \\
\text { nू. } \\
\text { के }\end{array}$ & 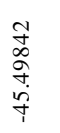 & $\begin{array}{l}\circ \\
\stackrel{2}{0} \\
\vdots \\
\text { ì }\end{array}$ & 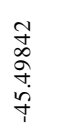 & 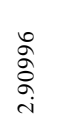 & 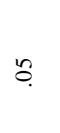 & $\tilde{\sigma}$ & 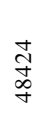 & 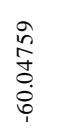 & 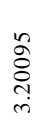 & & & $\frac{\&}{v}$ & $\stackrel{\&}{\nabla}$ \\
\hline 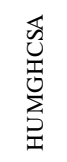 & $\begin{array}{l}\text { 命 } \\
\text { dै }\end{array}$ & 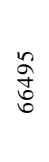 & 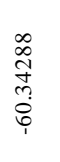 & 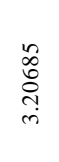 & $\begin{array}{l}\bar{a} \\
\bar{c} \\
\\
0 \\
0 \\
\vdots \\
1\end{array}$ & 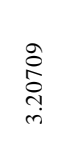 & 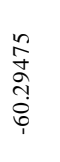 & $\begin{array}{l}\text { बे } \\
\stackrel{े}{0} \\
\text { ch }\end{array}$ & 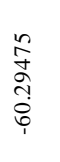 & $\begin{array}{l}\text { के } \\
\text { cे } \\
\text { ch }\end{array}$ & $\frac{8}{v}$ & $\stackrel{\circ}{\frac{8}{v}}$ & 令 & $\begin{array}{l}\text { Oे } \\
\text { م. } \\
0 \\
0 \\
0\end{array}$ & 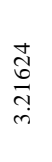 & & & $\frac{8}{v}$ & $\stackrel{ঃ}{\nabla}$ \\
\hline 旡 & 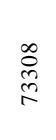 & 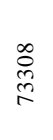 & 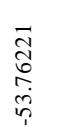 & 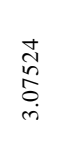 & $\begin{array}{l}\overrightarrow{\vec{m}} \\
\stackrel{\vec{n}}{\circ} \\
\vec{n}\end{array}$ & 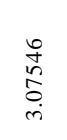 & $\frac{7}{\frac{7}{n}}$ & 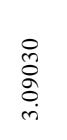 & 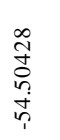 & 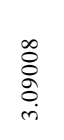 & $\frac{8}{v}$ & $\frac{8}{v}$ & 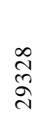 & 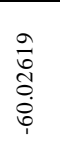 & 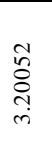 & 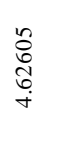 & 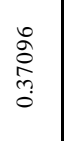 & $\frac{8}{v}$ & $\stackrel{ঃ}{v}$ \\
\hline 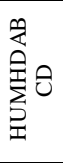 & 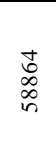 & 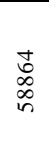 & $\begin{array}{l}\overrightarrow{0} \\
0 \\
0 \\
0 \\
0 \\
1\end{array}$ & 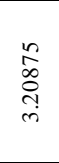 & $\begin{array}{l}\overrightarrow{0} \\
\stackrel{0}{0} \\
f \\
0 \\
1\end{array}$ & 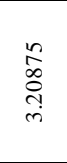 & 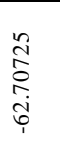 & 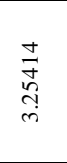 & 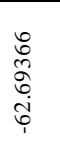 & 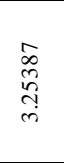 & $\frac{8}{v}$ & $\frac{8}{v}$ & $\begin{array}{l}\text { Dे } \\
\text { ले }\end{array}$ & 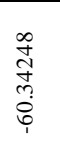 & 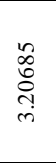 & & & $\frac{8}{v}$ & $\stackrel{\circ}{\nabla}$ \\
\hline 容 & 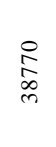 & $\underset{\substack{\infty \\
m}}{\stackrel{R}{\infty}}$ & $\begin{array}{l}\text { స్ } \\
\text { ñ. } \\
\text { in }\end{array}$ & 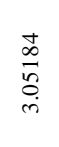 & 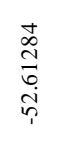 & 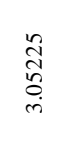 & 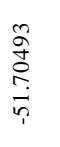 & 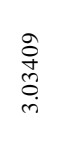 & 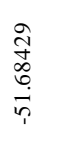 & 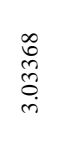 & $\frac{\&}{v}$ & $\frac{8}{v}$ & 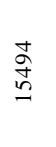 & $\begin{array}{l}n \\
n \\
\infty \\
\infty \\
0 \\
i\end{array}$ & $\begin{array}{l}\underset{\sigma}{\sigma} \\
\stackrel{\vec{\sigma}}{\rho}\end{array}$ & & & $\frac{\&}{v}$ & $\frac{\&}{v}$ \\
\hline 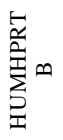 & 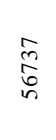 & $\begin{array}{l}\text { ma } \\
\hat{b} \\
b\end{array}$ & 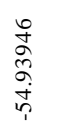 & $\begin{array}{l}\infty \\
\infty \\
\infty \\
0 \\
\dot{\infty}\end{array}$ & 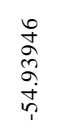 & $\begin{array}{l}\infty \\
\infty \\
\infty \\
\stackrel{\infty}{\infty}\end{array}$ & 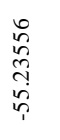 & 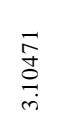 & 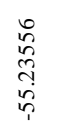 & 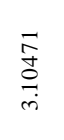 & $\frac{8}{v}$ & $\frac{8}{v}$ & $\begin{array}{l}\tilde{\hat{D}} \\
\text { ה్ }\end{array}$ & 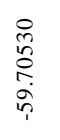 & $\frac{O}{\frac{7}{2}}$ & & & $\frac{8}{v}$ & $\stackrel{\&}{\mathrm{v}}$ \\
\hline $\begin{array}{l}0 \\
0 \\
\\
\end{array}$ & $\begin{array}{c}\hat{\sigma} \\
\stackrel{\sigma}{\sigma}\end{array}$ & 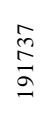 & 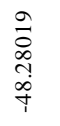 & 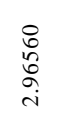 & 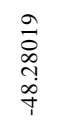 & $\begin{array}{l}0 \\
0 \\
0 \\
\text { oे }\end{array}$ & 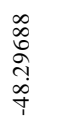 & 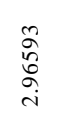 & 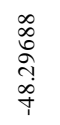 & 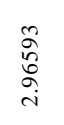 & $\frac{8}{v}$ & $\stackrel{\&}{v}$ & 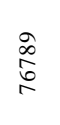 & 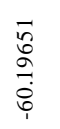 & 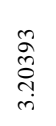 & & & $\frac{8}{v}$ & $\stackrel{\&}{\vec{v}}$ \\
\hline $\begin{array}{l}Z_{\mathbb{Z}} \\
\text { 语 }\end{array}$ & 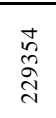 & 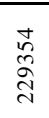 & 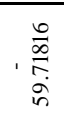 & 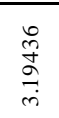 & , & $\begin{array}{l}\text { के } \\
\text { जे }\end{array}$ & 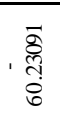 & $\begin{array}{l}\overline{0} \\
\text { d̦ } \\
\text { ju }\end{array}$ & $\begin{array}{r}\overline{8} \\
\text {, } \\
\text { d. }\end{array}$ & $\begin{array}{l}\bar{b} \\
\text { d̦ } \\
\text { ch }\end{array}$ & $\frac{\&}{v}$ & $\frac{8}{v}$ & $\begin{array}{l}\stackrel{t}{\Delta} \\
\sigma\end{array}$ & $\begin{array}{l}\infty \\
\frac{0}{0} \\
8 \\
0\end{array}$ & 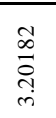 & & & $\stackrel{8}{\frac{1}{2}}$ & $\frac{8}{v}$ \\
\hline 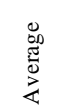 & & & & 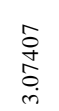 & & 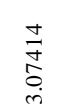 & & 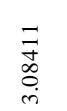 & & 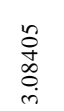 & & & & & 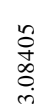 & & & & \\
\hline
\end{tabular}


Table 11: Compression Ratio \& Rate are shown in the Table for second data set

\begin{tabular}{|c|c|c|c|c|c|c|c|c|c|c|c|c|c|c|c|c|c|c|c|}
\hline \multirow{4}{*}{ 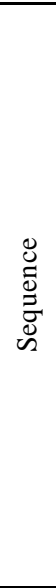 } & \multirow{4}{*}{ 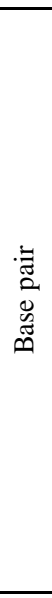 } & \multirow{4}{*}{ 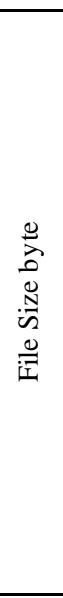 } & \multicolumn{10}{|c|}{ Cellular DNA } & \multicolumn{7}{|c|}{ Artificial DNA } \\
\hline & & & \multicolumn{2}{|c|}{ 芯苍 } & \multicolumn{2}{|c|}{ 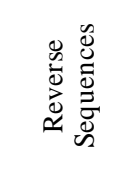 } & \multicolumn{2}{|c|}{ 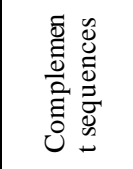 } & \multicolumn{2}{|c|}{ 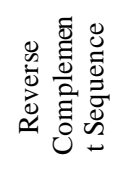 } & \multirow{2}{*}{\multicolumn{2}{|c|}{ 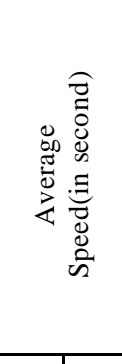 }} & \multirow{3}{*}{ 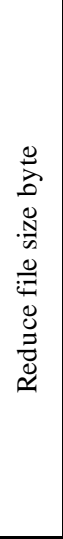 } & \multirow{3}{*}{ 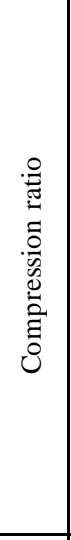 } & \multirow{3}{*}{ 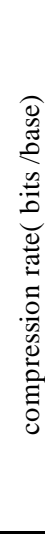 } & \multirow{3}{*}{ 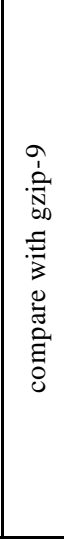 } & \multirow{3}{*}{ 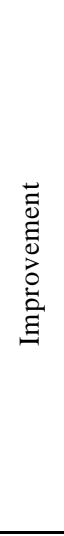 } & \multirow{2}{*}{\multicolumn{2}{|c|}{ 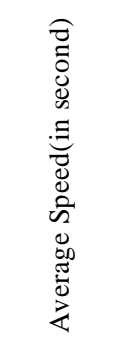 }} \\
\hline & & & $\begin{array}{l}\stackrel{0}{\mathbb{E}} \\
\stackrel{\Xi}{0}\end{array}$ & 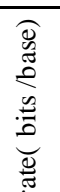 & $\begin{array}{l}\text { 莺 } \\
\text { 号 }\end{array}$ & 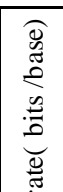 & $\begin{array}{l}\stackrel{0}{\overparen{D}} \\
\stackrel{\Xi}{0}\end{array}$ & 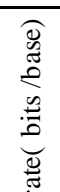 & $\begin{array}{l}\stackrel{0}{\overparen{T}} \\
\stackrel{\Xi}{0}\end{array}$ & 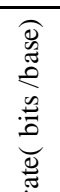 & & & & & & & & & \\
\hline & & & 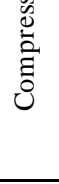 & 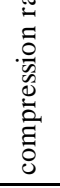 & 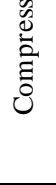 & 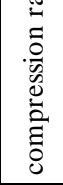 & 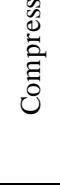 & 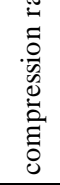 & 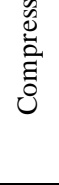 & 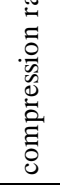 & 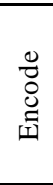 & 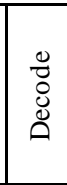 & & & & & & 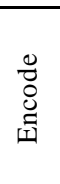 & 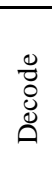 \\
\hline 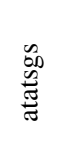 & 妾 & $\begin{array}{l}\text { f̂̀ } \\
\text { o }\end{array}$ & $\begin{array}{l}2 \\
\hat{n} \\
0 \\
m \\
\vdots \\
i \\
1\end{array}$ & $\begin{array}{l}\vec{\Xi} \\
\stackrel{\circ}{ } \\
\dot{m}\end{array}$ & 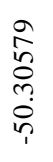 & $\begin{array}{l}\vec{\sigma} \\
\stackrel{0}{0} \\
\dot{m}\end{array}$ & 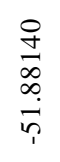 & $\begin{array}{l}\tilde{\sigma} \\
\hat{\sigma} \\
\tilde{r} \\
\dot{r}\end{array}$ & $\begin{array}{l}\stackrel{q}{d} \\
\infty \\
\infty \\
\stackrel{\sim}{r}\end{array}$ & 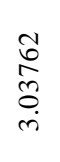 & $\frac{8}{v}$ & $\frac{\&}{\nabla}$ & $\underset{\infty}{\stackrel{\infty}{\infty}}$ & $\begin{array}{l}m \\
\hat{a} \\
m \\
\infty \\
\infty \\
i\end{array}$ & $\begin{array}{l}n \\
\hat{\sigma} \\
\frac{0}{0} \\
\text { r. }\end{array}$ & & & $\frac{\&}{\nabla}$ & $\frac{8}{\nabla}$ \\
\hline 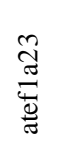 & స్రి & త్రి & $\frac{\infty}{\stackrel{\infty}{m}} \underset{m}{\stackrel{m}{\longrightarrow}}$ & 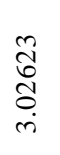 & 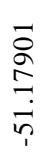 & 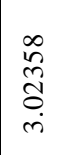 & 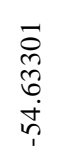 & 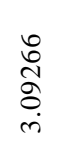 & $\begin{array}{l}\overrightarrow{0} \\
\text { ర్ర } \\
\dot{b} \\
\text { r. }\end{array}$ & $\begin{array}{l}\text { o } \\
\widetilde{\alpha} \\
\text { r. }\end{array}$ & $\stackrel{\circ}{\frac{8}{v}}$ & $\stackrel{\&}{\stackrel{亠}{v}}$ & 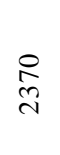 & 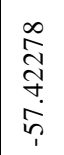 & 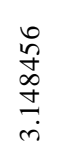 & & & 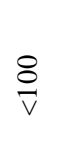 & $\frac{8}{v}$ \\
\hline 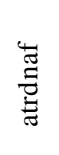 & $\underset{\stackrel{\Delta}{\sigma}}{\stackrel{\Delta}{\sigma}}$ & $\frac{t}{\stackrel{a}{g}}$ & $\begin{array}{l}\frac{a}{m} \\
\frac{\infty}{0} \\
\dot{b}\end{array}$ & $\begin{array}{l}\underset{\delta}{\tilde{D}} \\
\stackrel{\sim}{\infty}\end{array}$ & $\begin{array}{l}\vec{t} \\
\frac{m}{\infty} \\
\overrightarrow{0} \\
\stackrel{0}{n}\end{array}$ & 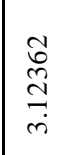 & 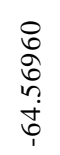 & $\frac{\text { ले }}{\stackrel{\text { సे }}{\text { r }}}$ & $\begin{array}{l}0 \\
0 \\
0 \\
n \\
0 \\
0\end{array}$ & $\frac{\vec{m}}{\hat{\sigma}}$ & $\stackrel{\circ}{\frac{8}{v}}$ & $\frac{\AA}{v}$ & $\begin{array}{l}\text { \& } \\
\stackrel{+}{a}\end{array}$ & $\begin{array}{l}\hat{a} \\
\text { a } \\
0 \\
0 \\
0\end{array}$ & 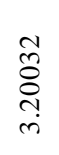 & & & 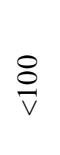 & $\stackrel{8}{\stackrel{े}{v}}$ \\
\hline 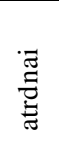 & $\begin{array}{l}\mathbf{D} \\
\stackrel{\sim}{n}\end{array}$ & $\begin{array}{l}\hat{\infty} \\
\hat{\sim} \\
\sim\end{array}$ & $\begin{array}{l}\tilde{c} \\
\tilde{n} \\
\hat{i} \\
r\end{array}$ & $\begin{array}{l}n \\
\tilde{o} \\
n \\
o \\
o \\
n\end{array}$ & 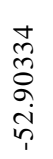 & $\begin{array}{l}8 \\
\infty \\
\infty \\
0 \\
\dot{r}\end{array}$ & $\begin{array}{l}\stackrel{0}{\widehat{\sigma}} \\
\stackrel{\infty}{0} \\
i\end{array}$ & $\begin{array}{l}n \\
\infty \\
\hat{ٍ} \\
\\
\end{array}$ & 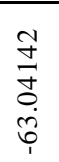 & 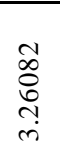 & $\stackrel{\circ}{\frac{8}{v}}$ & $\stackrel{ঃ}{\frac{\partial}{v}}$ & $\underset{\vec{\nabla}}{\stackrel{\partial}{\vec{n}}}$ & 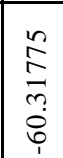 & 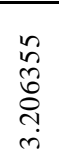 & & & $\frac{\&}{v}$ & $\frac{\AA}{v}$ \\
\hline $\begin{array}{l}\frac{1}{0} \\
\frac{0}{0} \\
\frac{0}{0}\end{array}$ & $\begin{array}{l}\text { dे } \\
\text { ò } \\
i n\end{array}$ & $\begin{array}{l}\text { aे } \\
\text { के } \\
\text { in }\end{array}$ & 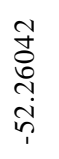 & 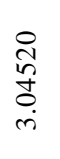 & 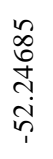 & 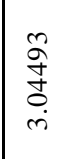 & 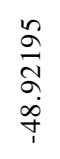 & 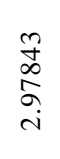 & $\begin{array}{l}\hat{0} \\
0 \\
o \\
o \\
\dot{0} \\
\dot{1}\end{array}$ & 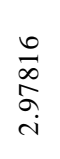 & $\frac{8}{v}$ & $\frac{8}{v}$ & $\begin{array}{l}\stackrel{\infty}{\infty} \\
\stackrel{\sim}{\sim}\end{array}$ & $\begin{array}{l}\text { م } \\
0 \\
0 \\
0 \\
0\end{array}$ & 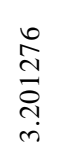 & $\begin{array}{l}n \\
0 \\
0 \\
0 \\
\dot{\sigma} \\
\dot{r}\end{array}$ & $\begin{array}{l}\infty \\
\dddot{2} \\
\hat{o} \\
\tilde{n} \\
0\end{array}$ & $\frac{\&}{v}$ & $\frac{8}{v}$ \\
\hline $\begin{array}{l}07 \\
0 \\
0 \\
0 \\
0 \\
0 \\
0 \\
0 \\
c\end{array}$ & $\underset{n}{\stackrel{n}{\sim}}$ & $\underset{\sim}{\stackrel{m}{N}}$ & 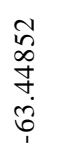 & 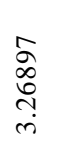 & 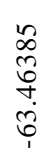 & $\begin{array}{l}\hat{\sigma} \\
\text { ò } \\
\text { rn }\end{array}$ & $\begin{array}{l}0 \\
+ \\
\infty \\
0 \\
0 \\
\\
i \\
1\end{array}$ & 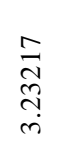 & $\begin{array}{l}0 \\
+ \\
0 \\
0 \\
0 \\
0 \\
\\
1\end{array}$ & $\begin{array}{l}\vec{N} \\
\underset{\sim}{\tilde{N}}\end{array}$ & $\frac{8}{v}$ & $\frac{8}{v}$ & $\begin{array}{l}\hat{\imath} \\
\hat{\infty} \\
\stackrel{\sim}{N}\end{array}$ & 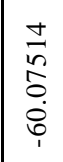 & 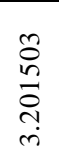 & & & $\frac{\&}{v}$ & $\stackrel{8}{\frac{8}{v}}$ \\
\hline 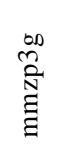 & $\begin{array}{l}\text { ले } \\
\infty \\
\stackrel{0}{0}\end{array}$ & $\begin{array}{l}\stackrel{\infty}{0}_{0}^{\infty} \\
\stackrel{0}{2}\end{array}$ & 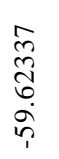 & 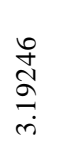 & $\begin{array}{l}\text { N} \\
\hat{0} \\
0 \\
\text { in }\end{array}$ & $\begin{array}{l}+ \\
\stackrel{\sigma}{\sigma} \\
\stackrel{m}{m}\end{array}$ & 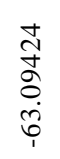 & $\begin{array}{l}\infty \\
\infty \\
\stackrel{\infty}{0} \\
\stackrel{n}{n}\end{array}$ & 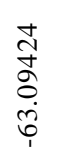 & 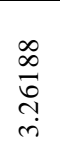 & $\frac{8}{v}$ & $\frac{\&}{v}$ & $\stackrel{尺}{\stackrel{F}{q}}$ & $\begin{array}{l}\text { N } \\
0 \\
0 \\
0 \\
1\end{array}$ & 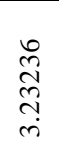 & & & $\frac{\&}{v}$ & $\frac{8}{v}$ \\
\hline $\begin{array}{l}\frac{a}{n} \\
60 \\
\frac{x}{x}\end{array}$ & $\stackrel{\infty}{\stackrel{\infty}{\varrho}}$ & $\underset{\substack{\infty \\
ٍ}}{2}$ & 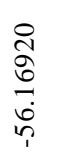 & 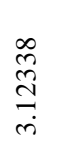 & 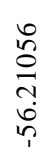 & $\frac{\vec{J}}{\stackrel{\vec{J}}{m}}$ & 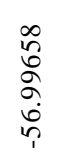 & $\frac{m}{\stackrel{\sigma}{m}}$ & $\begin{array}{l}\bar{v} \\
\tilde{\sigma} \\
b \\
b\end{array}$ & $\begin{array}{l}\frac{0}{\sigma} \\
\stackrel{m}{m}\end{array}$ & $\frac{8}{\vec{v}}$ & $\frac{\&}{v}$ & $\stackrel{\text { I }}{\stackrel{1}{\Sigma}}$ & $\begin{array}{l}\infty \\
\infty \\
\infty \\
\infty \\
0 \\
0 \\
0\end{array}$ & 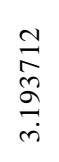 & & & $\frac{8}{v}$ & $\frac{8}{v}$ \\
\hline 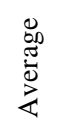 & & & & $\frac{a}{n}$ & & \begin{tabular}{l}
0 \\
\multirow{2}{0}{} \\
$\stackrel{0}{0}$ \\
$\dot{m}$
\end{tabular} & & 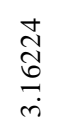 & & $\begin{array}{l}\hat{\sigma} \\
\hat{\delta} \\
\stackrel{i}{i}\end{array}$ & & & & & & & & & \\
\hline
\end{tabular}


Table 12: Comparison Compression Ratio \& Rate are shown in the Table for first data set

\begin{tabular}{|c|c|c|c|c|c|c|c|c|c|c|c|c|c|c|c|c|c|c|c|c|c|c|c|c|c|}
\hline \multirow{3}{*}{ 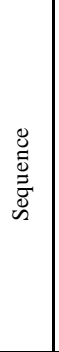 } & \multirow{3}{*}{ 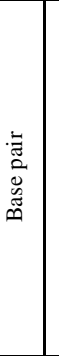 } & \multirow{3}{*}{ 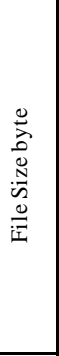 } & \multicolumn{7}{|c|}{ Using LUT algo. } & \multicolumn{7}{|c|}{ Using HUFF algo. } & \multicolumn{7}{|c|}{ Using LUTHUFF algo. } & \multirow{3}{*}{ 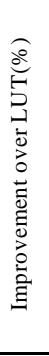 } & \\
\hline & & & \multirow{2}{*}{ 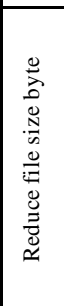 } & \multirow{2}{*}{ 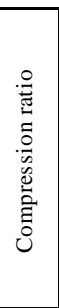 } & \multirow{2}{*}{ 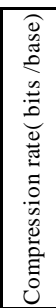 } & \multirow{2}{*}{ 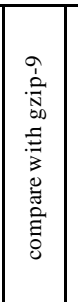 } & \multirow{2}{*}{ 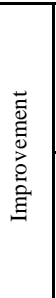 } & \multicolumn{2}{|c|}{ 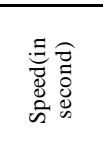 } & \multirow{2}{*}{ 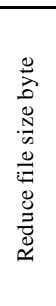 } & \multirow{2}{*}{ 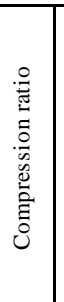 } & \multirow{2}{*}{ 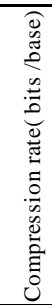 } & \multirow{2}{*}{ 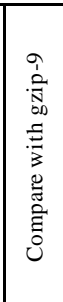 } & \multirow{2}{*}{ 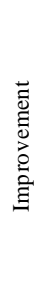 } & \multicolumn{2}{|c|}{ 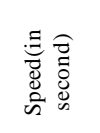 } & \multirow{2}{*}{ 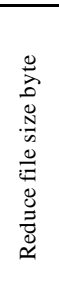 } & \multirow{2}{*}{ 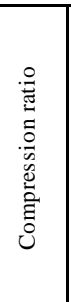 } & \multirow{2}{*}{ 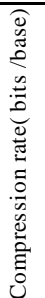 } & \multirow{2}{*}{ 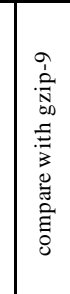 } & \multirow{2}{*}{ 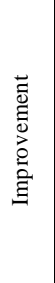 } & \multicolumn{2}{|c|}{ 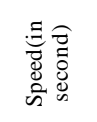 } & & \\
\hline & & & & & & & & 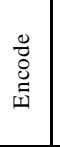 & 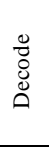 & & & & & & 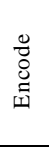 & 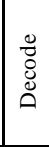 & & & & & & 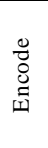 & 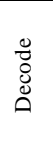 & & \\
\hline 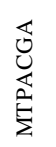 & 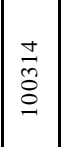 & 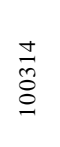 & 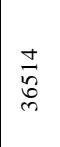 & $\begin{array}{l}\vec{\infty} \\
\infty \\
\infty \\
\vdots \\
\tilde{f} \\
f\end{array}$ & $\begin{array}{l}\hat{\sigma} \\
\stackrel{\vec{\sigma}}{\vec{j}} \\
\dot{i}\end{array}$ & & & $\frac{8}{v}$ & $\frac{\AA}{v}$ & 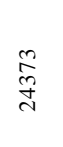 & $\begin{array}{l}\bar{m} \\
\stackrel{\vec{m}}{\infty} \\
\stackrel{0}{0}\end{array}$ & 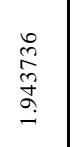 & & & $\frac{8}{0}$ & $\frac{9}{\circ}$ & $\begin{array}{l}\text { ठू } \\
\text { ते }\end{array}$ & 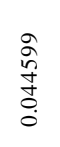 & 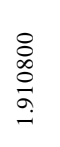 & & & $\frac{8}{0}$ & ते & & \\
\hline 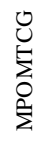 & $\begin{array}{l}0 \\
0 \\
0 \\
0 \\
-1 \\
-\end{array}$ & $\begin{array}{l}\infty \\
\stackrel{0}{0} \\
\infty \\
\stackrel{0}{-}\end{array}$ & 足 & $\begin{array}{l}\vec{\partial} \\
\vec{\Delta} \\
\dot{0} \\
\dot{b}\end{array}$ & 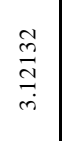 & & & $\approx$ & $\hat{o}$ & 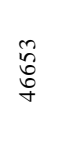 & 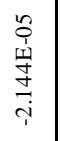 & 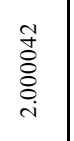 & & & 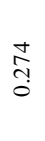 & 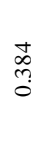 & $\begin{array}{l}\infty \\
\stackrel{\infty}{b} \\
\stackrel{\leftrightarrow}{+}\end{array}$ & 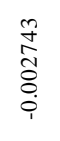 & 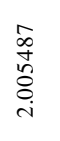 & & & $\begin{array}{l}\frac{t}{b} \\
\frac{0}{\sigma}\end{array}$ & 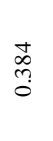 & & \\
\hline 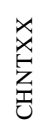 & 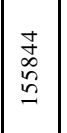 & 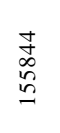 & $\begin{array}{l}\stackrel{\circ}{\circ} \\
\stackrel{\circ}{\circ}\end{array}$ & 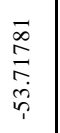 & $\begin{array}{l}m \\
\tilde{g} \\
\stackrel{+}{5} \\
\dot{r}\end{array}$ & & & $\stackrel{\circ}{\frac{8}{v}}$ & $\frac{\&}{v}$ & $\begin{array}{l}\widetilde{D} \\
\stackrel{\infty}{\infty}\end{array}$ & 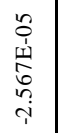 & $\begin{array}{l}\vec{n} \\
\vdots \\
\vdots \\
\text { ¿े }\end{array}$ & & & $\frac{\vec{d}}{\vec{\partial}}$ & $\begin{array}{c}\text { ले } \\
\text { है }\end{array}$ & పे & 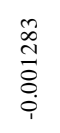 & 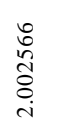 & & & $\frac{\partial}{0}$ & $\begin{array}{l}\text { ले } \\
\text { है }\end{array}$ & & \\
\hline 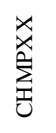 & 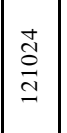 & 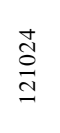 & $\begin{array}{c}\infty \\
\text { ò } \\
\text { \%े }\end{array}$ & $\begin{array}{l}\infty \\
0 \\
0 \\
\infty \\
0 \\
y \\
y\end{array}$ & $\begin{array}{l}\text { مे } \\
\hat{2} \\
\vdots \\
i\end{array}$ & & & $\approx$ & $\tilde{\delta}$ & $\begin{array}{l}\text { ă } \\
\text { ปे }\end{array}$ & 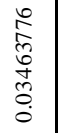 & 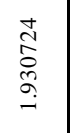 & & & $\begin{array}{l}\frac{t}{ \pm} \\
\\
0\end{array}$ & $\begin{array}{c}\stackrel{t}{y} \\
\text { ỳ }\end{array}$ & 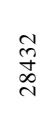 & $\begin{array}{l}n \\
\infty \\
\widetilde{0} \\
0 \\
0 \\
0 \\
0\end{array}$ & 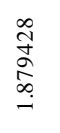 & & & $\frac{8}{0}$ & ते & & \\
\hline 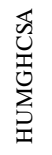 & 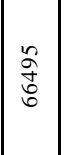 & $\begin{array}{l}\text { 吕 } \\
\text { do } \\
\text { d }\end{array}$ & 令 & 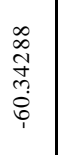 & \begin{tabular}{l}
$\infty$ \\
$\infty$ \\
\multirow{c}{0}{} \\
\end{tabular} & & & $\frac{8}{v}$ & $\frac{8}{v}$ & 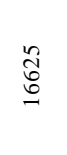 & 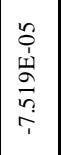 & $\begin{array}{l}0 \\
\stackrel{n}{0} \\
\stackrel{0}{a} \\
\text { i }\end{array}$ & & & $\begin{array}{l}\text { t. } \\
\text { o. } \\
0\end{array}$ & $\begin{array}{l}\text { t) } \\
\stackrel{0}{0}\end{array}$ & $\begin{array}{l}\overrightarrow{\overrightarrow{0}} \\
\stackrel{\circ}{-}\end{array}$ & 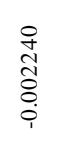 & $\begin{array}{l}\vec{\infty} \\
\stackrel{+}{+} \\
\stackrel{0}{0} \\
\text { i }\end{array}$ & & & 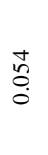 & $\frac{8}{0}$ & & \\
\hline 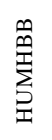 & 율 & $\stackrel{\infty}{\stackrel{\infty}{\curvearrowright}}$ & $\underset{\substack{\infty \\
\underset{N}{\infty}}}{\stackrel{\infty}{\infty}}$ & 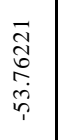 & $\begin{array}{l}\vec{J} \\
\tilde{n} \\
0 \\
\dot{m}\end{array}$ & 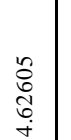 & 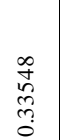 & $\frac{8}{v}$ & $\frac{O}{v}$ & $\begin{array}{l}\text { 赵 } \\
\stackrel{\infty}{=}\end{array}$ & 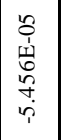 & $\begin{array}{l}\stackrel{\circ}{\circ} \\
\stackrel{े}{a} \\
\text { i }\end{array}$ & 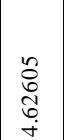 & $\begin{array}{l}\text { o. } \\
\stackrel{0}{0} \\
\text { in }\end{array}$ & $\frac{8}{0}$ & $\begin{array}{l}\frac{t}{6} \\
\stackrel{0}{0}\end{array}$ & 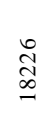 & $\begin{array}{l}0 \\
\frac{1}{n} \\
n \\
0 \\
0 \\
0\end{array}$ & 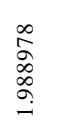 & 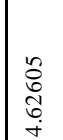 & 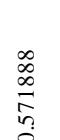 & 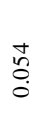 & $\frac{8}{0}$ & 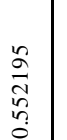 & 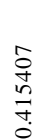 \\
\hline 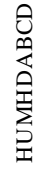 & $\begin{array}{l}\text { d } \\
\text { o } \\
\text { in } \\
n\end{array}$ & $\begin{array}{l}\text { da } \\
\text { o } \\
\infty\end{array}$ & 总 & 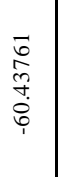 & 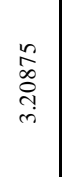 & & & $\frac{\AA}{v}$ & $\frac{\AA}{v}$ & $\underset{9}{\stackrel{7}{9}}$ & 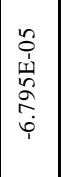 & $\begin{array}{l}\stackrel{\infty}{0} \\
\stackrel{0}{0} \\
\stackrel{d}{i} \\
i\end{array}$ & & & $\begin{array}{l}\text { t. } \\
\text { o. }\end{array}$ & 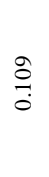 & $\begin{array}{l}\text { İ } \\
\text { d̆ }\end{array}$ & 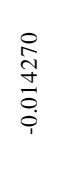 & 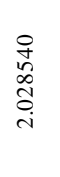 & & & & $\begin{array}{l}\stackrel{8}{0} \\
0\end{array}$ & & \\
\hline 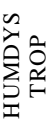 & $\underset{\substack{p \\
\text { m }}}{\stackrel{R}{n}}$ & 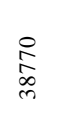 & $\begin{array}{l}\stackrel{8}{2} \\
\text { I }\end{array}$ & $\begin{array}{l}\text { त्స్ } \\
\text { ì } \\
\text { ì }\end{array}$ & 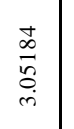 & & & $\frac{\circ}{v}$ & $\frac{\AA}{v}$ & $\begin{array}{l}\text { t } \\
\text { oू }\end{array}$ & 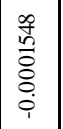 & $\begin{array}{l}\text { oे } \\
\text { ळे } \\
\text { ठ } \\
\text { i. }\end{array}$ & & & $\begin{array}{l}\text { 童 } \\
\text { o. }\end{array}$ & 嶽 & $\stackrel{\infty}{\stackrel{\infty}{\circ}}$ & $\begin{array}{l}0 \\
0 \\
0 \\
0 \\
0 \\
0 \\
0\end{array}$ & $\begin{array}{l}\hat{\hat{O}} \\
+ \\
\infty \\
\stackrel{0}{-}\end{array}$ & & & $\frac{8}{0}$ & 嶽 & & \\
\hline 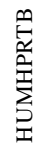 & 芯 & 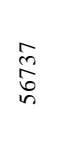 & 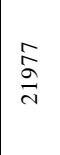 & 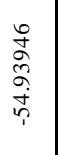 & $\begin{array}{l}\infty \\
\infty \\
\infty \\
0 \\
\dot{r}\end{array}$ & & & $\frac{\circ}{v}$ & $\stackrel{\circ}{\frac{\partial}{v}}$ & 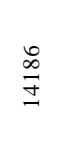 & 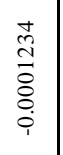 & 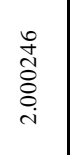 & & & 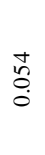 & $\frac{8}{0}$ & 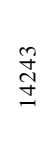 & 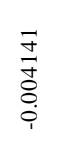 & 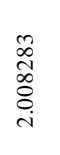 & & & $\begin{array}{l}\text { t. } \\
\stackrel{\text { on }}{0}\end{array}$ & $\begin{array}{l}\text { 莡 } \\
\text { o. }\end{array}$ & & \\
\hline 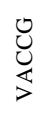 & 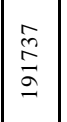 & 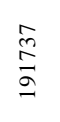 & $\stackrel{\hat{s}}{\stackrel{5}{r}}$ & 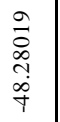 & 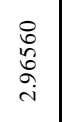 & & & $\frac{\&}{v}$ & $\frac{\&}{v}$ & 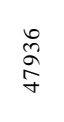 & 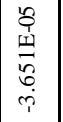 & 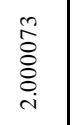 & & & $\frac{\vec{c}}{\vec{\partial}}$ & 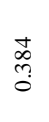 & 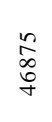 & $\begin{array}{l}\hat{\text { Oे }} \\
\text { ते } \\
\text { o. }\end{array}$ & 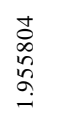 & & & $\begin{array}{l}\frac{t}{6} \\
0 \\
0\end{array}$ & के & & \\
\hline 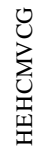 & 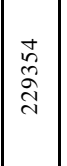 & 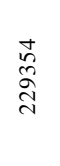 & $\begin{array}{l}\stackrel{\infty}{\infty} \\
\frac{\infty}{a}\end{array}$ & $\begin{array}{l}\frac{0}{\infty} \\
\stackrel{\infty}{\circ} \\
\stackrel{a}{i}\end{array}$ & 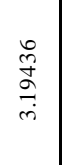 & & & $\frac{8}{v}$ & $\frac{\AA}{v}$ & $\begin{array}{l}q \\
\text { 足 } \\
\text { in }\end{array}$ & 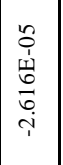 & 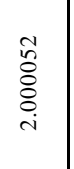 & & & $\begin{array}{c}\text { ले } \\
\text { है }\end{array}$ & $\begin{array}{l}\text { 孛 } \\
\text { d. }\end{array}$ & $\begin{array}{l}\vec{D} \\
\stackrel{\infty}{i}\end{array}$ & $\begin{array}{l}: \\
: \\
0 \\
0 \\
0 \\
0\end{array}$ & $\begin{array}{l}\frac{N}{\sigma} \\
\stackrel{0}{0} \\
\stackrel{i}{i}\end{array}$ & & & ते & $\begin{array}{l}\text { 孛 } \\
\text { d. }\end{array}$ & & \\
\hline 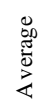 & & & & & 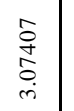 & & & & & & & $\begin{array}{l}\text { O. } \\
\stackrel{0}{\circ} \\
\stackrel{\circ}{\circ}\end{array}$ & & & & & & & 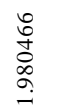 & & & & & & \\
\hline
\end{tabular}


Table 13: Table shown the comparative result for second data set

\begin{tabular}{|c|c|c|c|c|c|c|c|c|c|c|c|c|c|c|c|c|c|c|c|c|c|c|c|c|c|}
\hline \multirow{3}{*}{ 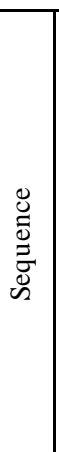 } & \multirow{3}{*}{ 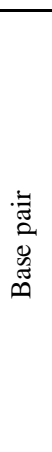 } & \multirow{3}{*}{ 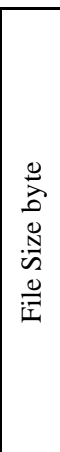 } & \multicolumn{7}{|c|}{ Using LUT algo. } & \multicolumn{7}{|c|}{ Using HUFF algo. } & \multicolumn{7}{|c|}{ Using LUTHUFF algo. } & \multirow{3}{*}{ 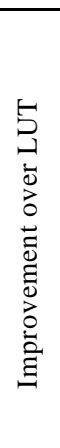 } & \multirow{3}{*}{ 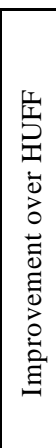 } \\
\hline & & & \multirow{2}{*}{ 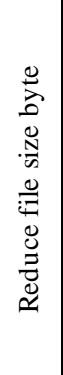 } & \multirow{2}{*}{ 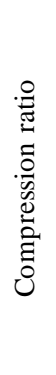 } & \multirow{2}{*}{ 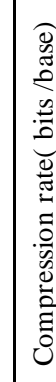 } & \multirow{2}{*}{ 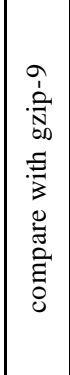 } & \multirow{2}{*}{ 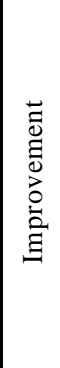 } & \multicolumn{2}{|c|}{ 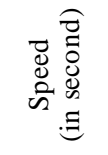 } & \multirow{2}{*}{ 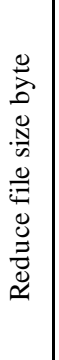 } & \multirow{2}{*}{ 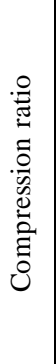 } & \multirow{2}{*}{ 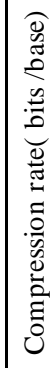 } & \multirow{2}{*}{ 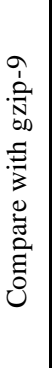 } & \multirow{2}{*}{ 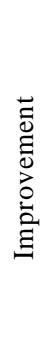 } & \multicolumn{2}{|c|}{ 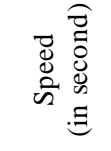 } & \multirow{2}{*}{ 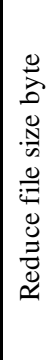 } & \multirow{2}{*}{ 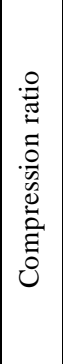 } & \multirow{2}{*}{ 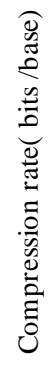 } & \multirow{2}{*}{ 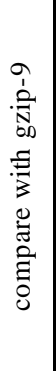 } & \multirow{2}{*}{ 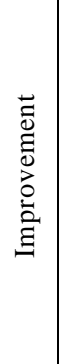 } & \multicolumn{2}{|c|}{ 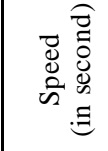 } & & \\
\hline & & & & & & & & 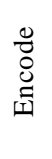 & 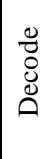 & & & & & & 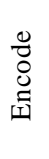 & $\begin{array}{l}0 \\
8 \\
0 \\
\Xi\end{array}$ & & & & & & 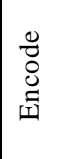 & $\begin{array}{l}0 \\
\tilde{0} \\
\tilde{\Xi} \\
0\end{array}$ & & \\
\hline 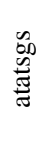 & 每 & 宊 & $\begin{array}{l}\text { त్ } \\
\text { n్ }\end{array}$ & 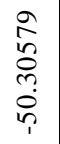 & $\begin{array}{l}\vec{\Xi} \\
\stackrel{0}{0} \\
\dot{r}\end{array}$ & & & $\frac{8}{v}$ & $\frac{8}{v}$ & $\stackrel{m}{\underset{\sim}{\sim}}$ & 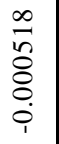 & $\begin{array}{l}\hat{\tilde{o}} \\
\stackrel{0}{\sigma} \\
i \\
\text { in }\end{array}$ & & & 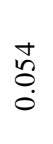 & $\stackrel{8}{v}$ & 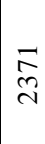 & $\begin{array}{l}0 \\
\stackrel{0}{0} \\
0 \\
0 \\
0 \\
\dot{0}\end{array}$ & 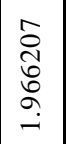 & & & 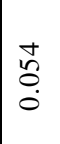 & 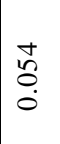 & & \\
\hline 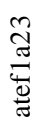 & ปิ & ปิ & $\stackrel{\infty}{\stackrel{\infty}{\sim}}$ & $\begin{array}{l}\infty \\
\stackrel{\infty}{\vec{m}} \\
\stackrel{m}{r}\end{array}$ & $\begin{array}{l}\text { O̦ } \\
\tilde{D} \\
\text { r. }\end{array}$ & & & $\frac{\AA}{\vec{v}}$ & $\frac{8}{\vec{v}}$ & 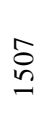 & 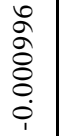 & $\begin{array}{l}\tilde{\partial} \\
\stackrel{\partial}{\sigma} \\
i \\
i\end{array}$ & & & $\stackrel{ঃ}{\stackrel{\circ}{2}}$ & $\frac{8}{v}$ & 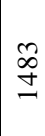 & 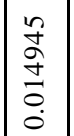 & $\begin{array}{l}\vec{\sigma} \\
\stackrel{2}{a} \\
\stackrel{0}{-}\end{array}$ & & & $\frac{\AA}{v}$ & $\frac{8}{\vec{v}}$ & & \\
\hline 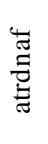 & $\stackrel{ \pm}{8}$ & $\stackrel{t}{\Xi}$ & $\frac{\circ}{2}$ & $\begin{array}{l}\frac{d}{m} \\
\vec{\infty} \\
\vec{b} \\
\vec{b}\end{array}$ & $\begin{array}{l}\underset{\tilde{D}}{\tilde{C}} \\
\stackrel{\sim}{m}\end{array}$ & & & $\stackrel{\circ}{\stackrel{\circ}{v}}$ & $\frac{8}{\vec{v}}$ & $\begin{array}{l}n \\
\text { co } \\
\text { d. }\end{array}$ & $\begin{array}{l}\text { oे } \\
\text { ठे } \\
\vdots \\
\text { o. }\end{array}$ & $\begin{array}{l}\infty \\
\stackrel{\infty}{a} \\
\vec{\Xi} \\
\stackrel{i}{i}\end{array}$ & & & $\stackrel{ঃ}{\stackrel{\circ}{v}}$ & 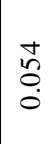 & 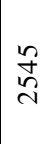 & $\begin{array}{l}0 \\
\hat{n} \\
0 \\
0 \\
0 \\
1\end{array}$ & 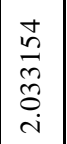 & & & $\stackrel{\&}{\vec{v}}$ & $\stackrel{\circ}{\frac{8}{2}}$ & & \\
\hline 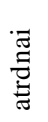 & $\begin{array}{l}\hat{\infty} \\
\hat{\sim}\end{array}$ & $\begin{array}{l}\hat{\infty} \\
\stackrel{\sim}{n}\end{array}$ & $\overrightarrow{\vec{N}}$ & $\begin{array}{l}\stackrel{\sim}{N} \\
\stackrel{n}{n} \\
i\end{array}$ & $\begin{array}{l}\text { n } \\
0 \\
0 \\
0\end{array}$ & & & $\frac{8}{v}$ & $\frac{8}{v}$ & $\stackrel{\widetilde{\Omega}}{\stackrel{\Omega}{2}}$ & \begin{tabular}{l}
0 \\
\multirow{2}{*}{} \\
oे \\
0 \\
0
\end{tabular} & $\begin{array}{l}\bar{\alpha} \\
\bar{\alpha} \\
\vec{a}\end{array}$ & & & $\stackrel{Ð}{\mathrm{v}}$ & $\begin{array}{l}\text { 离 } \\
\text { o. } \\
0\end{array}$ & ले & $\begin{array}{l}n \\
\infty \\
0 \\
1 \\
0 \\
0\end{array}$ & $\begin{array}{l}\hat{a} \\
0 \\
0\end{array}$ & & & $\frac{8}{v}$ & $\frac{\AA}{v}$ & & \\
\hline $\begin{array}{l}\frac{1}{0} \\
\frac{0}{0} \\
\frac{8}{8}\end{array}$ & $\begin{array}{c}\text { aे } \\
\text { d. } \\
\text { in }\end{array}$ & $\begin{array}{c}\underset{a}{d} \\
\text { D. } \\
i n\end{array}$ & ָे & 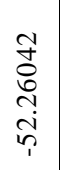 & $\begin{array}{l}\stackrel{\sim}{N} \\
\tilde{q} \\
\dot{c} \\
\dot{r}\end{array}$ & 焉 & m. & $\stackrel{ঃ}{\frac{\partial}{v}}$ & $\frac{8}{v}$ & 趈 & 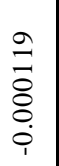 & 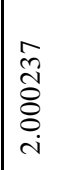 & 岁 & $\begin{array}{l}0 \\
n \\
\vdots\end{array}$ & 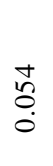 & $\begin{array}{l}\frac{\partial}{0} \\
0\end{array}$ & 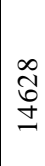 & $\begin{array}{l}m \\
\frac{m}{t} \\
\dot{8} \\
\dot{0}\end{array}$ & 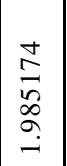 & $\begin{array}{l}\text { do } \\
\stackrel{f}{ }\end{array}$ & $\begin{array}{l}0 \\
n \\
:\end{array}$ & $\begin{array}{l}+ \\
\stackrel{0}{0} \\
:\end{array}$ & $\begin{array}{l}\frac{8}{0} \\
\frac{0}{0}\end{array}$ & $\begin{array}{l}n \\
n \\
i \\
i\end{array}$ & $\begin{array}{l}\infty \\
\infty \\
\dot{r}\end{array}$ \\
\hline 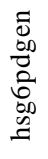 & $\underset{\sim}{\stackrel{n}{\sim}}$ & 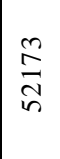 & $\frac{\vec{m}}{\vec{v}}$ & 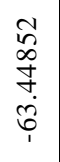 & $\begin{array}{l}\hat{a} \\
\infty \\
0 \\
\tilde{n} \\
\end{array}$ & & & $\stackrel{\circ}{\stackrel{\circ}{2}}$ & $\stackrel{8}{\frac{\Xi}{v}}$ & 乍 & 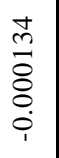 & 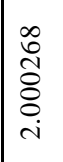 & & & $\begin{array}{l}\stackrel{8}{\circ} \\
0\end{array}$ & $\frac{a}{0}$ & $\underset{\stackrel{+}{g}}{\stackrel{+}{2}}$ & 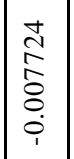 & 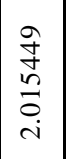 & & & $\begin{array}{l}\text { tr } \\
\text { o. } \\
0\end{array}$ & 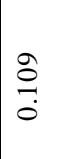 & & \\
\hline 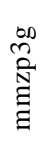 & 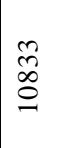 & $\begin{array}{l}\widehat{\infty} \\
\stackrel{\infty}{=} \\
\stackrel{0}{-}\end{array}$ & $\underset{\tilde{F}}{\tilde{F}}$ & 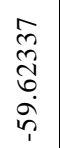 & 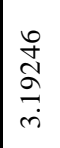 & & & $\stackrel{\&}{\stackrel{亠}{v}}$ & $\stackrel{\circ}{\stackrel{\circ}{v}}$ & $\underset{\sim}{\stackrel{ }{N}}$ & 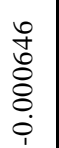 & 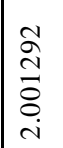 & & & $\stackrel{\&}{\frac{\delta}{v}}$ & 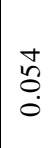 & $\underset{\sim}{\stackrel{m}{\sim}}$ & 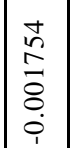 & 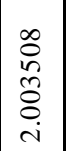 & & & \begin{tabular}{l}
\multirow{2}{*}{} \\
o. \\
0
\end{tabular} & $\frac{\&}{v}$ & & \\
\hline $\begin{array}{l}\frac{N}{5} \\
\text { Do } \\
\frac{x}{x}\end{array}$ & $\stackrel{\infty}{\stackrel{\Omega}{\Omega}}$ & 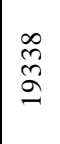 & $\begin{array}{l}n \\
n \\
n\end{array}$ & 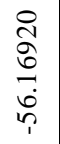 & 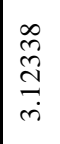 & & & $\stackrel{̊}{\vec{v}}$ & $\stackrel{ঃ}{\frac{8}{v}}$ & 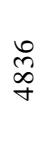 & $\begin{array}{l}\overline{0} \\
\stackrel{0}{0} \\
\dot{i} \\
\dot{1}\end{array}$ & $\begin{array}{l}\overrightarrow{\widehat{d}} \\
\stackrel{\Delta}{0} \\
\text { i. }\end{array}$ & & & 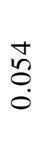 & 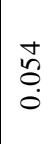 & 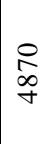 & $\begin{array}{l}\text { fे } \\
\tilde{w} \\
\tilde{o} \\
0 \\
\dot{0}\end{array}$ & $\begin{array}{l}0 \\
0 \\
0 \\
o \\
0 \\
0 \\
i \\
i\end{array}$ & & & $\frac{\&}{v}$ & $\begin{array}{l}\text { to } \\
\text { Oे } \\
0\end{array}$ & & \\
\hline 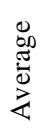 & & & & & $\frac{\frac{v}{n}}{\frac{n}{c}}$ & & & & & & & $\begin{array}{l}\hat{\sigma} \\
\stackrel{0}{0} \\
\stackrel{8}{i} \\
i\end{array}$ & & & & & & & $\begin{array}{l}\hat{\alpha} \\
\text { बे } \\
\text { बे }\end{array}$ & & & & & & \\
\hline
\end{tabular}


A Compression \& Encryption Algorith m on DNA

Table 15: Percentage of encryption

\begin{tabular}{|c|c|c|c|c|c|}
\hline $\begin{array}{l}\text { Input file } \\
\text { size (byte) }\end{array}$ & $\begin{array}{c}\text { Compress } \\
(\%)\end{array}$ & $\begin{array}{l}\text { Swapping } \\
\text { at Level }\end{array}$ & $\begin{array}{c}\text { Lavenstein } \\
\text { Dist. }\end{array}$ & $\begin{array}{c}\% \text { effect on } \\
\text { actual text }\end{array}$ & $\begin{array}{c}\% \text { of } \\
\text { encryption }\end{array}$ \\
\hline \multirow{4}{*}{71077} & \multirow{4}{*}{58} & 1 & 64471 & 94.58 & 100 \\
\hline & & 2 & 64278 & 93.893 & 60.3 \\
\hline & & 3 & 64178 & 93.685 & 51.85 \\
\hline & & 4 & 63985 & 93.049 & 44.32 \\
\hline \multirow{4}{*}{43958} & \multirow{4}{*}{60} & 1 & 45365 & 94.22 & 100 \\
\hline & & 2 & 45123 & 93.717 & 58.17 \\
\hline & & 3 & 44930 & 93.52 & 52.93 \\
\hline & & 4 & 44838 & 92.78 & 47.67 \\
\hline \multirow{4}{*}{36514} & \multirow{4}{*}{61} & 1 & 28499 & 93.897 & 100 \\
\hline & & 2 & 28432 & 93.7 & 62.44 \\
\hline & & 3 & 28350 & 93.329 & 51.33 \\
\hline & & 4 & 28087 & 92.251 & 44.48 \\
\hline \multirow{4}{*}{14790} & \multirow{4}{*}{62} & 1 & 16266 & 93.85 & 100 \\
\hline & & 2 & 16242 & 93.62 & 61.14 \\
\hline & & 3 & 16238 & 92.8 & 55.67 \\
\hline & & 4 & 16204 & 91.9 & 48.95 \\
\hline \multirow{4}{*}{7550} & \multirow{4}{*}{67} & 1 & 8582 & 93.65 & 100 \\
\hline & & 2 & 8508 & 93.525 & 58.33 \\
\hline & & 3 & 8482 & 92.588 & 50.02 \\
\hline & & 4 & 8462 & 91.48 & 44.16 \\
\hline
\end{tabular}

From the above table- 4 we can conclude with the ratio of encryption of about $45 \%$ to $60 \%$, we could achieve the ratio of damage to the file of nearly $94 \%$ in some cases.

We also observe that if we change at the top level (1) then Lavenstein Distance is at highest point \& \% of damage is highest. When we change at lower level Lavenstein Distance is decrease \& \% of damage also decrease. According to above results we draw two graphs for five different real text cases; one is effectiveness on the output text by different input file size at different level (Graph-I) and other is effectiveness on the output text file by increasing encryption. From fig. a, we observe if the file size is decreased then \%of modification from the actual te xt is decreased and from Graph-II; if \%of encryption is increased then \%of modification from the actual text is also increased.

Effectiveness on the output text by different input size at different level.
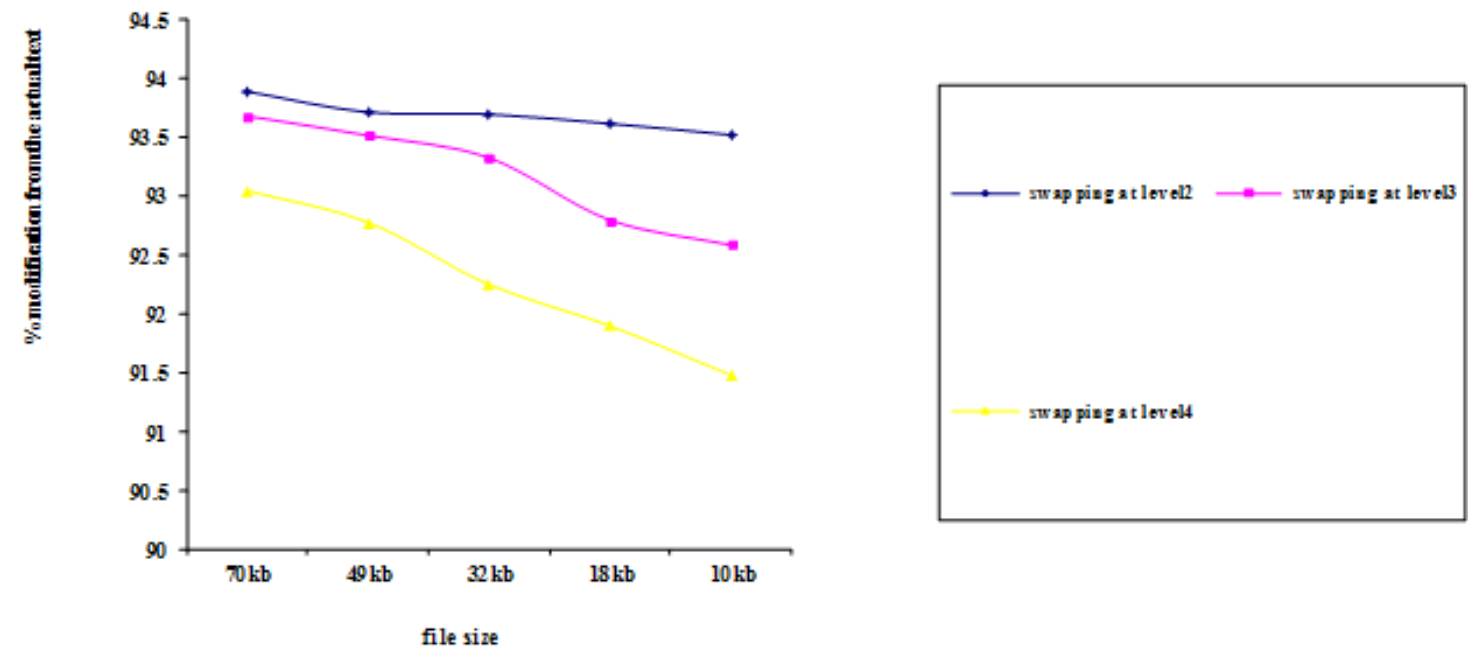

Fig. 12: (\% modification for the actual text vs. file size) 


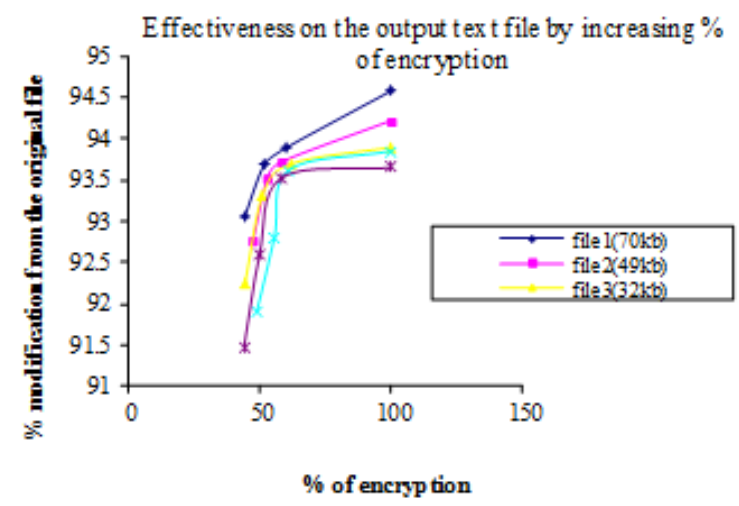

\section{Using Scheme-II}

From the table 16 we observe that if we apply swapping at lower level then percentage of encryption is also reduced but original text will affect minimum $85 \%$. This also provides higher security if we consider two binary values as a key and encrypt them.

According to above results we draw graph for three different real text cases. From Graph-III; if \%of encryption is increased then \%of modification from the actual text is also increased.

Fig. 13: (\% modification from the originalfile vs. $\%$ of encryption)

Table 16: Effect using level charge

\begin{tabular}{|c|c|c|c|c|c|c|c|c|}
\hline \multirow{3}{*}{$\begin{array}{l}\text { Input file } \\
\text { size (byte) }\end{array}$} & \multirow{3}{*}{ Compress (\%) } & \multicolumn{4}{|c|}{ Specification of two nodes } & \multirow{3}{*}{$\begin{array}{l}\text { Lavenstein } \\
\text { Dist. }\end{array}$} & \multirow{3}{*}{$\begin{array}{c}\% \text { of } \\
\text { encryption }\end{array}$} & \multirow{3}{*}{$\begin{array}{c}\% \text { effect on } \\
\text { actual text }\end{array}$} \\
\hline & & \multicolumn{2}{|r|}{$1^{\text {st }}$ node } & \multicolumn{2}{|c|}{$2^{\text {nd }}$ node } & & & \\
\hline & & Level & Binary value & Level & Binary value & & & \\
\hline \multirow{4}{*}{71077} & \multirow{4}{*}{58} & 3 & 110 & 4 & 0100 & 64182 & 51 & 92.13 \\
\hline & & 6 & 111111 & 4 & 0010 & 60985 & 47.19 & 89.049 \\
\hline & & 4 & 0101 & 5 & 11111 & 63116 & 49.3 & 90.6 \\
\hline & & 5 & 00001 & 6 & 111111 & 61089 & 46.5 & 87.69 \\
\hline \multirow{4}{*}{43958} & \multirow{4}{*}{60} & 5 & 10100 & 4 & 0001 & 41545 & 49.8 & 90.15 \\
\hline & & 2 & 11 & 3 & 000 & 44838 & 53.13 & 93.125 \\
\hline & & 3 & 001 & 4 & 1110 & 44797 & 51.06 & 91.98 \\
\hline & & 2 & 00 & 2 & 10 & 45790 & 54.68 & 94.02 \\
\hline \multirow{4}{*}{36514} & \multirow{4}{*}{61} & 4 & 1000 & 3 & 101 & 27997 & 51 & 93.65 \\
\hline & & 5 & 00101 & 3 & 101 & 28087 & 47.98 & 91.051 \\
\hline & & 2 & 01 & 2 & 10 & 29502 & 53.39 & 94.65 \\
\hline & & 4 & 0000 & 4 & 1111 & 28511 & 49.35 & 91.47 \\
\hline
\end{tabular}

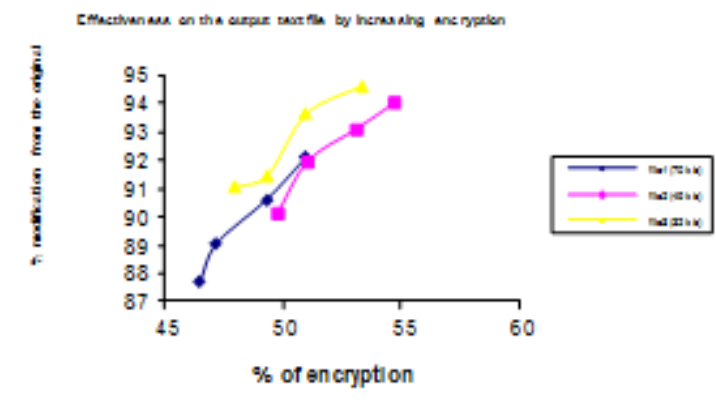

Fig. 14: (\% modification from the original file vs. $\%$ of encryption)

Table 17:

\begin{tabular}{|c|c|c|c|}
\hline Sequence & Base pair/File size & GZIP & BZIP2 \\
\hline atatsgs & 9647 & 2.1702 & 2.15 \\
\hline atef1a23 & 6022 & 2.0379 & 2.15 \\
\hline atrdnaf & 10014 & 2.2784 & 2.15 \\
\hline atrdnai & 5287 & 1.8846 & 1.96 \\
\hline celk07e12 & 58949 & & \\
\hline hsg6pdgen & 52173 & 2.2444 & 2.07 \\
\hline mmzp3g & 10833 & 2.3225 & 2.13 \\
\hline xlxfg512 & 19338 & 1.8310 & 1.80 \\
\hline Average & & & \\
\hline
\end{tabular}

Table 18:

\begin{tabular}{|c|c|c|c|}
\hline Sequence & $\begin{array}{c}\text { Base pair } \\
\text { /File size }\end{array}$ & GZIP & BZIP2 \\
\hline MTPACGA & 100314 & 2.2919 & 2.12 \\
\hline MPOMTCG & 186609 & 2.3288 & 2.17 \\
\hline CHNTXX & 155844 & 2.3345 & 2.18 \\
\hline CHMPXX & 121024 & 2.2818 & 2.12 \\
\hline HUMGHCSA & 66495 & 2.0648 & 1.31 \\
\hline HUMHBB & 73308 & 2.2450 & \\
\hline HUMHDABCD & 58864 & 2.2389 & 2.07 \\
\hline HUMDYSTROP & 38770 & 2.3618 & 2.18 \\
\hline HUMHPRTB & 56737 & 2.2662 & 2.09 \\
\hline VACCG & 191737 & 2.2518 & 2.09 \\
\hline HEHCMVCG & 229354 & 2.3275 & 2.17 \\
\hline
\end{tabular}

The results from Table $12 \& 13$ show our algorith ms to be the best solution for client side decryption decompression with the shortest and linearly increasing decompression time. However, our algorithm doesn't compress sequences as much as others for many of the cases in the compression ratio table $17 \& 18$ but it provide high information security. This is because our algorithm uses less than 2 bits to represent one nucleotide 
In order to compare the overall performance, we conducted further studies involving sending actual sequence files of varying sizes (without compression) to measure the calculated time $\left(\mathrm{T}_{\mathrm{c}}\right)$ needed for the transmission from the source to the destination. Then we compressed those files using both compression \& encryption algorithms. The total time $\mathrm{T}$, defined as the sum of the encryption compressed file transmission time $\left(\mathrm{T}_{\mathrm{ec}}\right)$ plus the client side decompression time $\left(\mathrm{T}_{\mathrm{dd}}\right)$, is measured by both these methods.

\section{Result Discussion}

We can feel the time of program running since they are in second level. Some ones even cost minutes or hours of time to run. But our algorithm runs almost $10^{3}$ times faster. Our algorithm performances is better than it in both compression ratio and elapsed time. Our algorith $m$ is very useful in database storing. We can keep sequences as records in database instead of maintaining them as files. By just using the pre-coding routine, users can obtain original sequences in a time that can't be felt. Additionally, our algorithm can be easily implemented while some of them will take you more time to program.

From these experiments, we conclude that pre coding matching patter are same in all type of sources and pre coding Look up Table plays a key role in finding similarities or regularities in DNA sequences. Straight line graph declared that compression rate are same in all type of sources. Output file contain ASCII character with un matched a,u,g and c so, it can provide information security which is very important for data protection over transmission point of view. Also, at the time of encoding require authenticate input base pair (from a,t,g and c) and ASCII character starting position for derivate LUT table, produce original sequence which is encode by this techniques. These techniques provide the high security to protect nucleotide sequence in a particular source. Not necess ary to derive all combinational result because this method created $24 \mathrm{X} 2=48$ different types of LUT but total sub-string are same in all cases but their position is different only.

Here we can get better security than static LUT. In static LUT encode/decode does not depends on LUT sub-string input value from a,t,g and c, but dynamic LUT must depends on LUT sub-string input value from a,t,g and c. In that situation authentication is very important.

Encoding time "Sub-sequence size-1" base segment are remaining, (if at the end of file segment are not match exactly with pre-coded table)We cannot find any arrangement in table-I or table-II. In these circumstances, we just write the orig inal segment into destination file. To increase the probability of compaction we match the sequence in other orientation such as reverse, complement and reverse complement the input file. But experimental result showing no mean ingful changes are found using other orientation taking as input.

The ratio of decompression time to original transmission time of the uncompressed sequence file $\left(\mathrm{T}_{\mathrm{dd}} / \mathrm{T}_{\mathrm{c}}\right)$, reduces with increasing file size. This means our client side decryption decompression technique with our algorithm is a better choice for larger sequence files. Our client side decryption decompression technique can be implemented by a genome search agent and decryption decompression time can be estimated by two empirical equations according to our experiments.

The graph of compression time versus sequence file length is somewhat non-linear, because of the complexity that arises when the sequence length is not divisible by 4 , which means that not all the bit pairs in the last byte of the compressed file may represent valid nucleotides. One solution to this problem is to add an extra byte at the end of compressed file which is the count (1-4) of the number of valid nucleotides in the previous byte.

Our algorithm combines moderate encryption compression with reduced decryption decompression time to achieve the best performance for client side sequence delivery compared with existing techniques. Its linearity in decompression time and close linearity in compression time make it an effective compression tool for commercial usage. Given, for a particular connection speed, the efficiency achieved using our algorith m; this compression technique is recommended for transmission of queried sequence files.

\section{Conclusion}

In this article, we discussed a new DNA compression algorithm whose key idea is dynamic LUT. This compression algorithm gives a good model for compressing DNA sequences that reveals the true characteristics of DNA sequences. The compression results of dynamic LUT for DNA sequences also indicate that our method is more effective than many others. Dynamic LUT is able to detect more regularity in DNA sequences, such as mutation and crossover, and achieve the best compression results by using this observation. Dynamic LUT fails to achieve higher compression ratio than others standard method, but dynamic LUT has provide very high information security and high authentication user.

In this work we have performed computational experiments to selectively encrypt the compressed text of different sizes generated through static Huffman encoding technique and compare the effectiveness in terms of dissimilarity from the original file if one has to decrypt without the key and the resistance of the cipher text from the attacks based on statistical property of the plain text. We have used two different schemes; in scheme-I swapping of nodes is done at 
specified level based on key and in scheme-II swapping is done between two specified nodes at different levels. We have found from our experiments, the effectiveness of the encryption system increases as the level at which swapping is done, increases. We have achieved in the both the scheme with $45 \%$ to $60 \%$ encryption of orig inal text, near about $90 \%$ to $93 \%$ of damage in original file.

We have also measures the redundancy on the basis of weighted frequency. We have observed weighted frequency of an input text and encrypted text are nearly $8: 1$ ratio. That mean in case of input text and output text, number of characters having same frequency maintain the ratio approx $8: 1$. So the probability of frequency analysis attack is low.

In our experiments of selective encryption of text, on the basis of statistical property of words therein, we have found that to get $90 \%$ effectness on actual text then \%of encryption should be more than 60 , since number of distinguishable words are huge and their frequency is much less than number of frequency of characters. This approach has a good scope as a selective encryption scheme because of the fact that in a text of any language the articles, verbs, and prepositions have a higher frequency compared to the other words relevant to the core content of the text.

The problem s mall key space has to be sorted out to effectively apply this encryption system in real world.

\section{Future Work}

We are trying to do more, such as combining our dynamic LUT pre-coding routine with other compression algorithms, to revise our algorithm in order to improve its performance. We are trying to build a finite LUT which implements the mapping relationship of our coding process.

Here in this work, we have taken into consideration the statistical property of a character or a word while doing compression. Instead, one can consider the statistical property of any number characters or bits, the number of bits may be provided by the user depending on the application or may be chosen automatically on the basis of entropy. In that case this encryption technique may be extended to any type of media. The effectiveness of selective encryption may be studied for the otherstatistical compression algorithms available.

\section{Acknowledgements}

Above all, author is grateful to all our colleagues for their valuable suggestion, moral support, interest and constructive criticism of this study.

\section{References}

[1] M. Li and P. Vitányi, An Introduction to Kolmogorov Complexity and Its Applications, 2nd ed. New York: Springer-Verlag, 1997.

[2] R. Curnow and T. Kirkwood, "Statistical analysis of deo xyribonucleic acid sequence data-a review," J. Royal Statistical Soc., vol. 152, pp. 199-220, 1989.

[3] S. Grumbach and F. Tahi, "A new challenge for compression algorithms: Genetic sequences," J. Inform. Process. Manage., vol. 30, no. 6, pp. 875 866, 1994.

[4] É. Rivals, O. Delgrange, J.P. Delahaye, M.Dauchet, M.O. Delorme et al., "Detection of significant patterns by compression algorithms: the case of Approximate Tandem Repeats inDNAsequences," CABIOS, vol. 13, no. 2, pp. 131-136,1997.

[5] K. Lanctot, M. Li, and E.H. Yang, "Estimating DNA sequence entropy,"in Proc. SODA 2000, to be published.

[6] D. Loewenstern and P. Yianilos, "Significantly lower entropy estimates for natural DNA sequences," J. Comput. Biol., to be published (Preliminary version appeared in a DIMACS workshop, 1996.)

[7] Two algorithms for constructing efficient huffman-code based reversible variable length Codes Chia-Wei Lin; Ja-Ling Wu; Yuh-Jue Chuang

[8] Bentley J. L., Sleator D.D., Tarjan R.E., and Wei V., "A locally adaptive data compression scheme", Communications of the ACM, 29(4), 320-330, 1986.

[9] J. G. Cleary and I. H. Witten. Data compression using adaptive coding and partial string matching. IEEE Trans. Comm., COM-32(4):396-402, April 1984.

[10] C. E. Shannon, "A mathematical theory of communication," The Bell System Technical Journal, vol. 27, 1948.

[11] D. A. Huffman, "A method for the construction of minimum-redundancy codes,"Proc. IRE, vol. 40, pp. 1098-1101, 1952.

[12] On the competitive optimality of Huffman codes by Thomas. M. Cover.

[13] Guaranteed Synchronization of Huffman Codes with Known Position of Decoder Marek Tomasz Biskup, Wojciech Plandowski,

[14] C. E. Shannon, "Communication theory of secrecy systems," Bell Systems Technical Journal, v. 28, October 1949, pp. 656-715. 
[15] Chen, L., Lu, S. and Ram J. 2004. "Compressed Pattern Matching in DNA Sequences". Proceedings of the 2004 IEEE Computational Systems Bioinformatics Conference (CSB 2004)

[16] Toshiko Matsumoto, Kunihiko Sadakane and Hiroshi Imai. " Biological Sequence Compression Algorithms", Genome Informatics $11: 43-52$ (2000)

[17] S. Grumbach and F. Tahi, "A new challenge for compression algorithms: Genetic sequences," J. Inform. Process. Manage., vol. 30, no. 6, pp. 875866, 1994.

[18] Xin Chen, San Kwong and Mine Li, "A Compression Algorithm for DNA Sequences Using Approximate Matching for Better Compression Ratio to Reveal the True Characteristics of DNA", IEEE Engineering in Medicine and Biology,pp 61-66,July/August 2001.

[19] Adam Drozdek “ Elements of Data Compression”, Vikas Publishing House (2002)

[20] T. Matsumoto,K.Sadakame and H. Imani, "Biological sequence compression algorithm", Genome Informatics 11:43-52 (2000).

[21] ASCII code. [Online]. Available: http://www.asciitable.com

[22] National Center for Biotechnology Information, http://www.ncbi.nlm.nih.gov

\section{Author's Profiles}

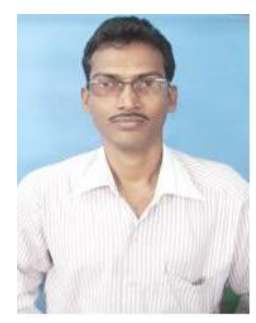

Syed Mahamud Hossein is perusing Ph.D for Computer Science in Vidyasagar University. $\mathrm{He}$ had received his post graduate degree in Computer Applications from Swami Ramanand Teerth Marathawada University, Nanded and Master of Engineering in Information Technology from West Bengal University of Technology, Kolkata. He has worked as the Senior Lecturer in Haldia Institute of Technology, Haldia, Lecturer on contract basis in Panskura Banamali College, Panskura and Lecturer in Iswar Chandra Vidyasagar Polytechnic, Govt. of West Bengal, Jgargram. Presently he is working as a District Officer, Regional Office, Kolaghat, Directorate of Vocational Educational \& Training, West Bengal since 2010. His research interests includes Bioinformatics, Compression Techniques \& Cryptography, Design and Analysis of Algorithms \& Development of Software Tools. He is a member of professional societies like Computer Society of India \& Indian Science Congress Association.
How to cite this paper: Syed Mahamud Hossein, S.Roy,"A Compression \& Encryption Algorithm on DNA Sequences Using Dynamic Look up Table and Modified Huffman Techniques", International Journal of Information Technology and Computer Science(IJITCS), vol.5, no.10, pp.39-61, 2013. DOI: 10.5815/ijitcs.2013.10.05 